\title{
The paradigm theory of lifestyle: A theoretical study
}

\author{
Abdullah Kurshid Abdullah ${ }^{1}$
}

Shahlaa Wali Jabbar ${ }^{2}$

Received: Mar10, 2018 Reviewed: Apr 01, 2018
Accepted: Apr13, 2018

\begin{abstract}
This paper tries to investigate the paradigm theories of lifestyle. Most researchers in the last two centuries argue that the concept of the lifestyle has replaced the concept of the social class; their evidence is that the ability of the vertical class to analyze behavior, values and perspective is less than lifestyle of individuals. That doesn't mean that classes are erased, but it makes question the ability of analysis in this concept, and their proof of that is the existence of some links between the individuals and their difference social status, we can no longer have a true picture of our social reality through the social class. In such a circumstance, the concept of lifestyle is structure, because unlike the class concept it doesn't define the logic and the concept of lifestyle. Rather, this concept shows some activities, gains (income) which interact with each other and enable the social researcher to manifest its forms. The concept of lifestyle is not a substitute for the concept of class, but it pares the way for social sciences to conduct research on the experiences of daily life and how individuals consume and invest, and that identity derived from the experience as well as conducting research on the characteristics of the individual and group. Through this concept, social researches are able to observe the creative role of characters better than before and avoid the use of concept of social status and class, which has scattered meanings.
\end{abstract}

Keywords:Lifestyle, Social Class, Social Status, Consumption, Social Identity

\section{Recommended citation:}

Abdullah A. K. \& Jabbar S. W. (2018). The paradigm theory of lifestyle: A theoretical study. International Journal of Kurdish Studies 4 (2), 580 - 594.doi: 10.21600/ ijoks.454573

\footnotetext{
${ }^{1}$ Assc. Prof. Dr., Social Organization, Salahaddin University, College of Art, Sociology, Erbil, Iraq E-mail: abdullah.abdullah@su.edu.krd

${ }^{2} \mathrm{Ph} . \mathrm{D}$ Student and Lecturer, Urban Sociology, Salahaddin University, College of Art, Sociology, Erbil, Iraq, Email: shahlaa.jabbar@su.edu.krd
} 


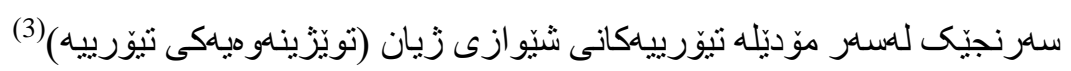

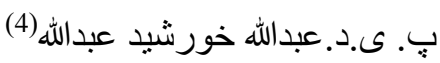

شهلاء ولى جبار (5)

يوخته

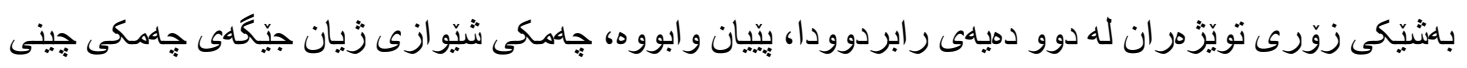

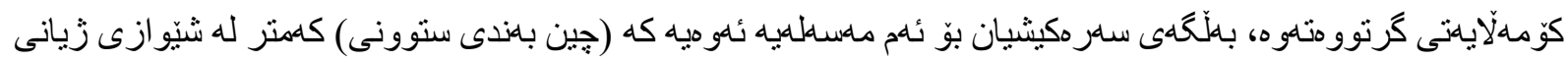

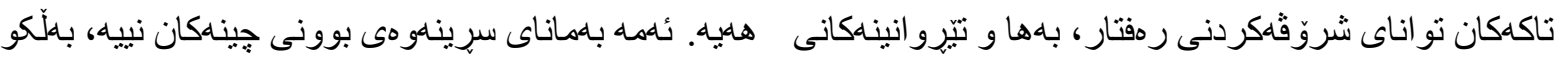

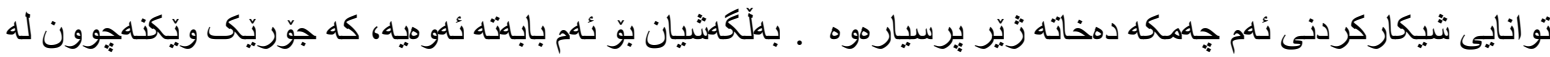

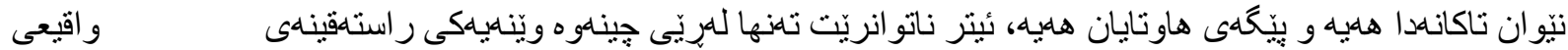

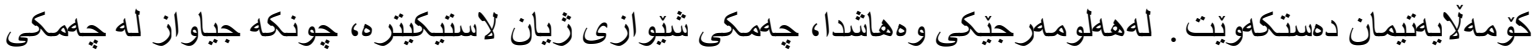

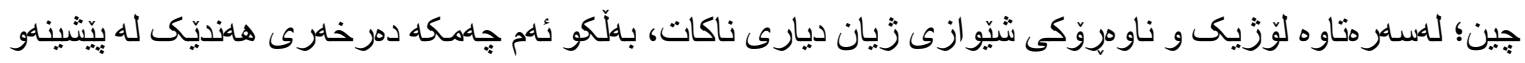

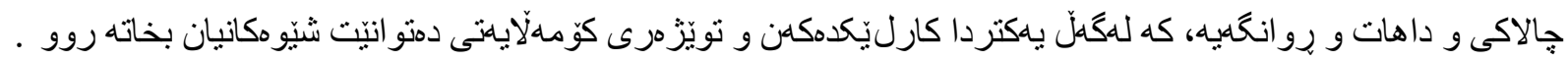

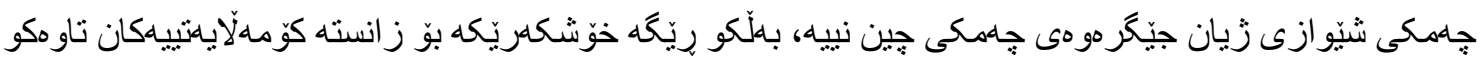

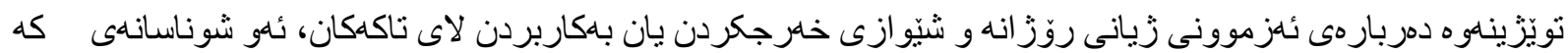

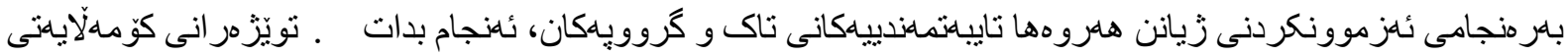

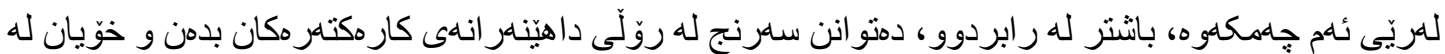

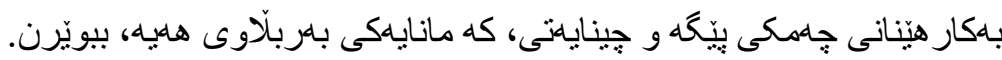

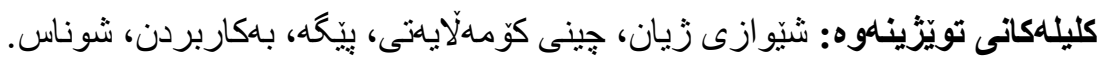

\section{بليشهاكى}

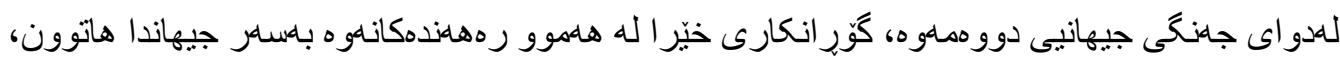

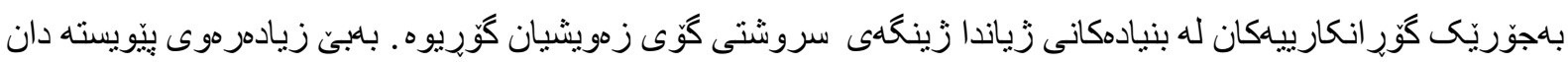

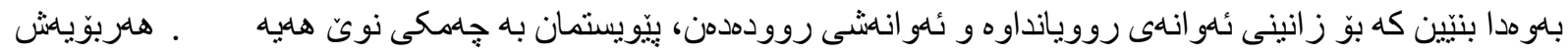

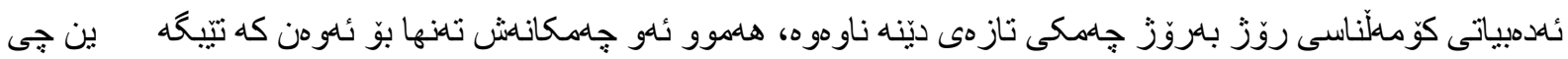

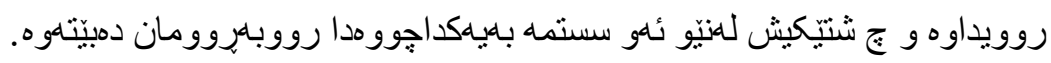

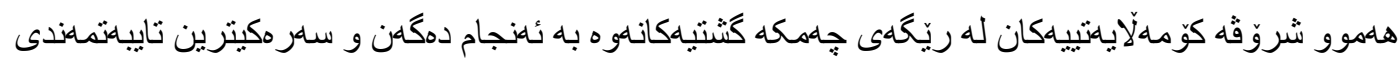

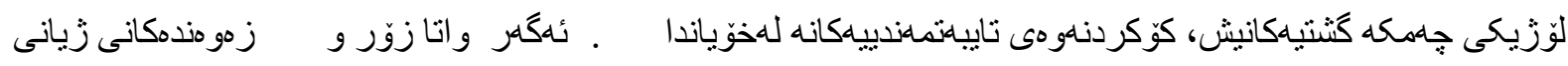

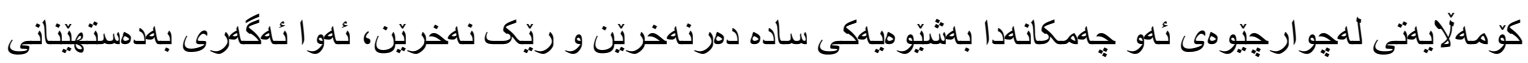

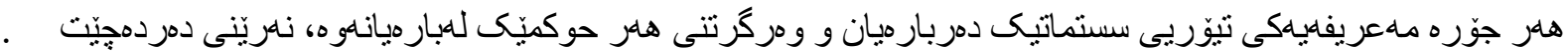

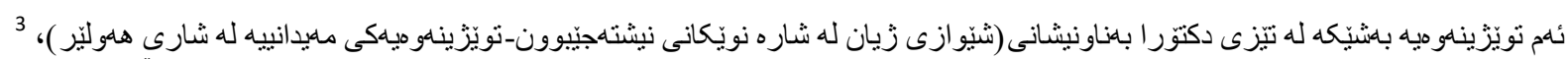

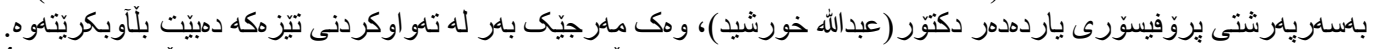

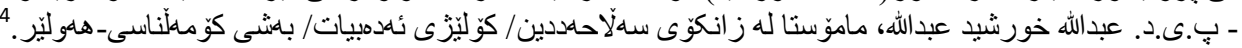

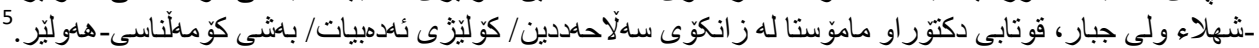




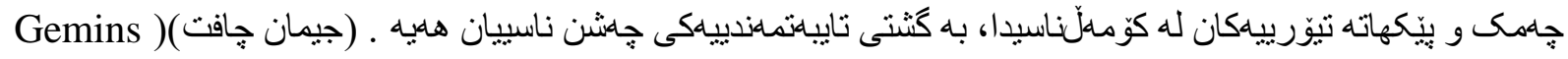

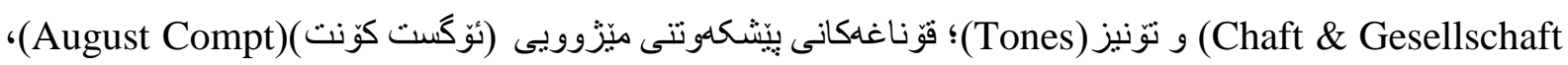

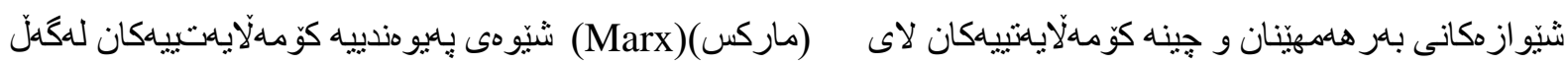

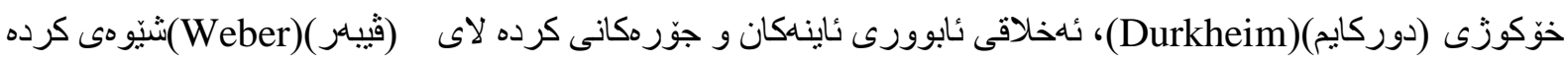

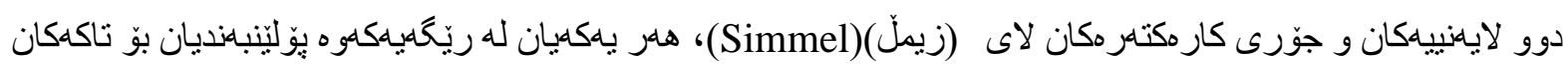

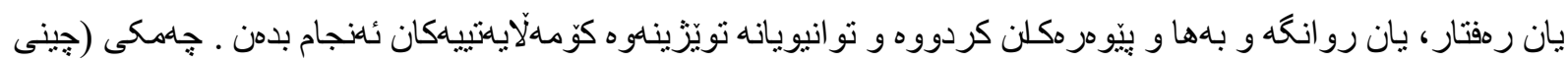

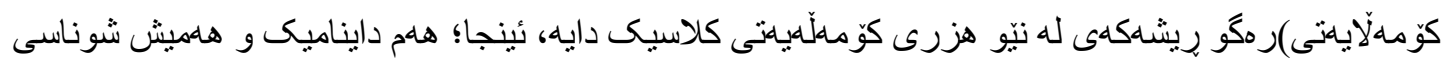

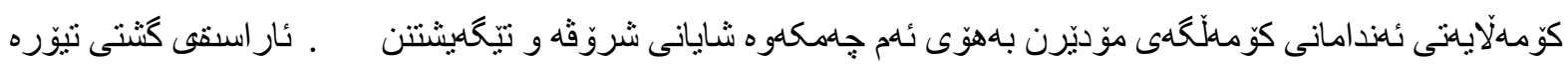

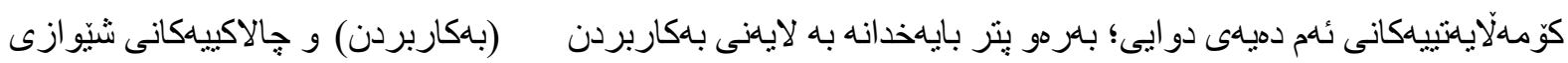

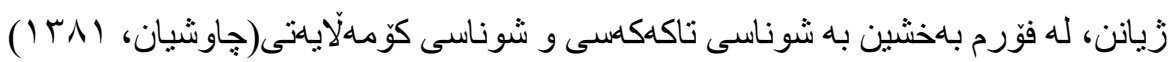

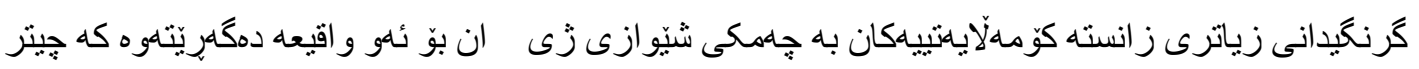

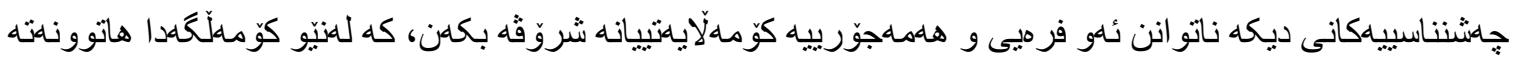

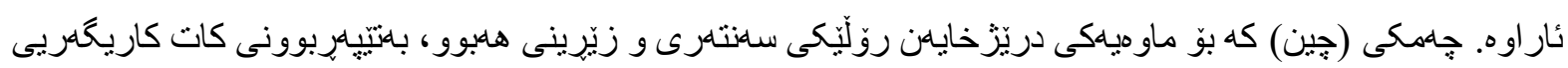

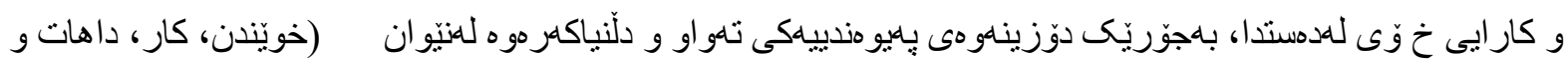

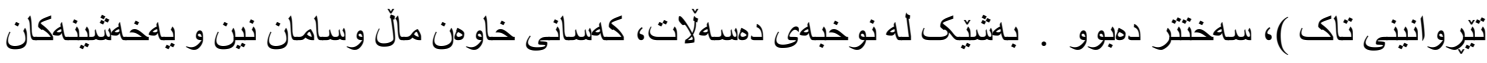

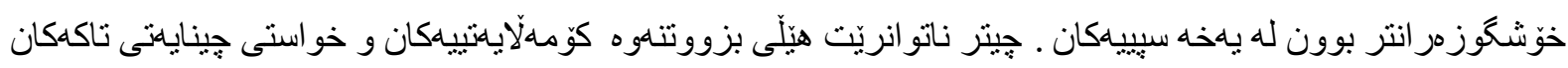

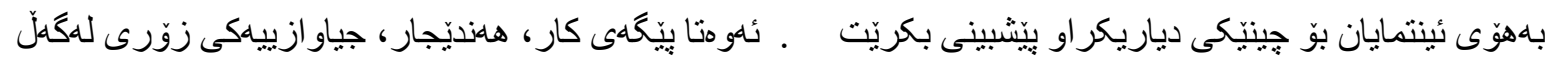
خوينّدوارى و داهات و دمسهلاّتدا هليه.

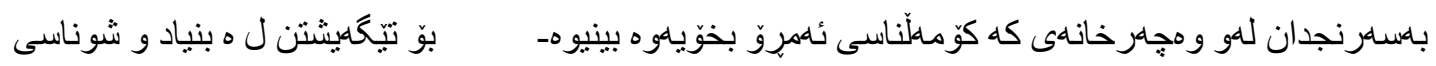

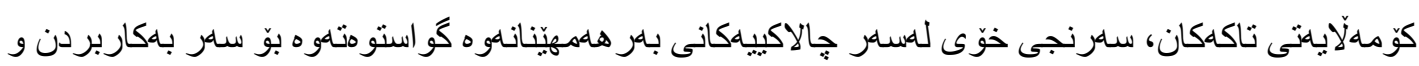

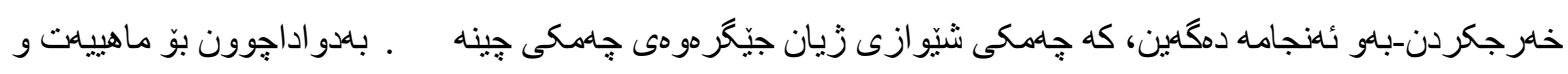

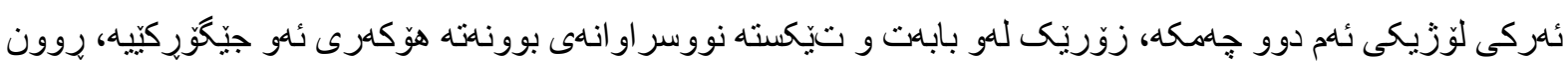
دهكاتهوه.

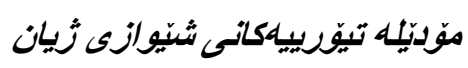

\section{إنقرشتاين قبلن (Thorstein Veblen)}

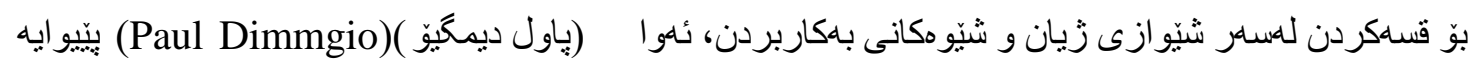

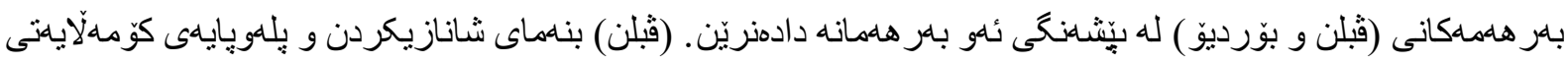

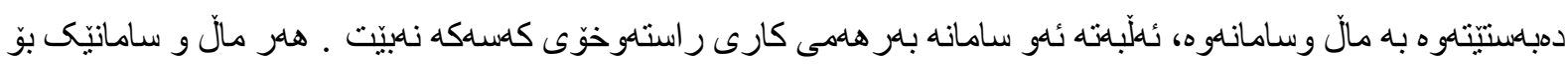

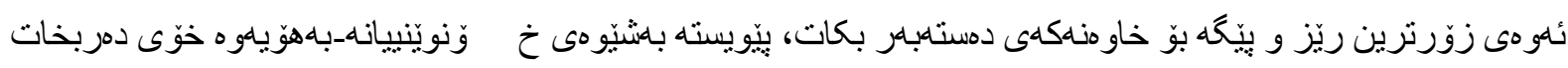

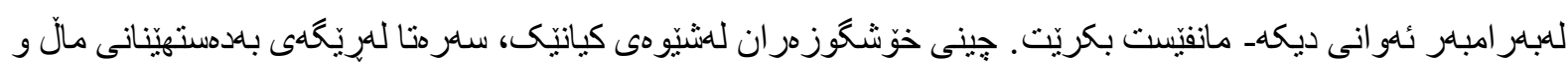

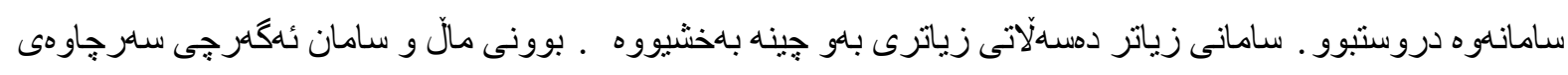

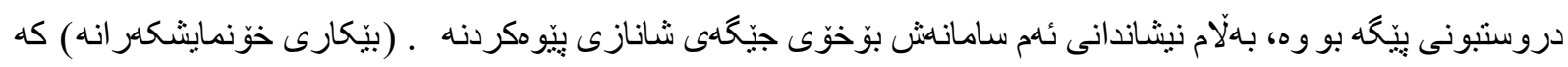

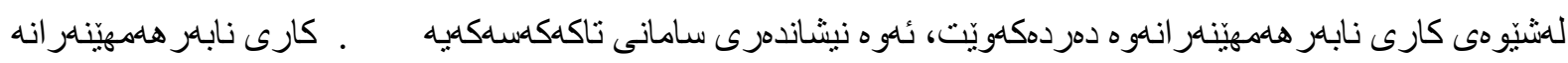




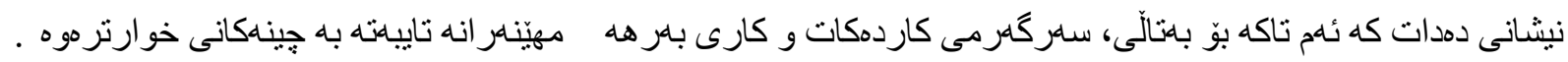

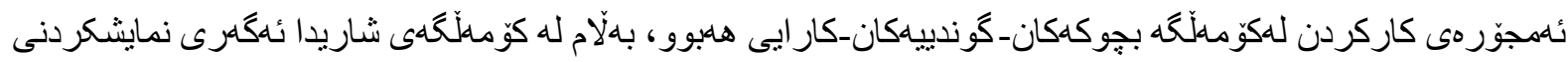

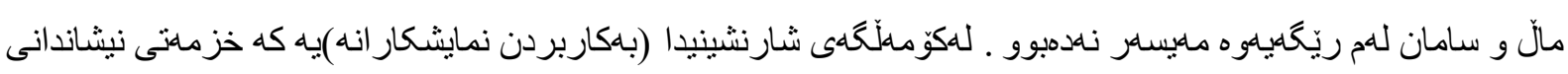

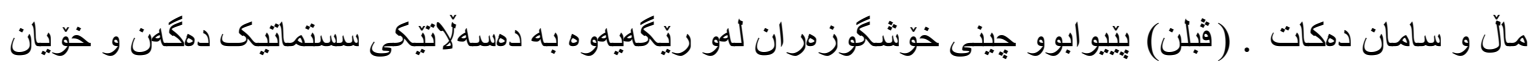

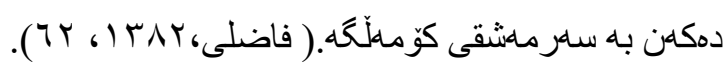

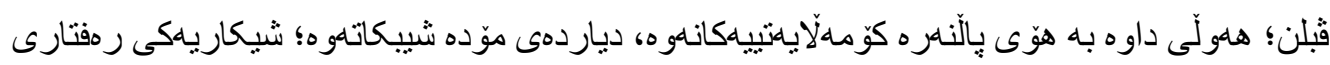

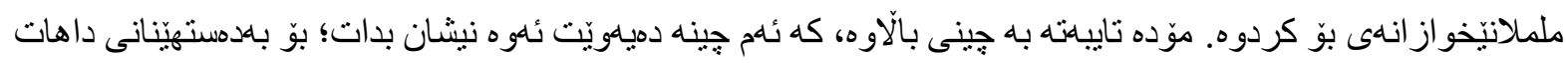

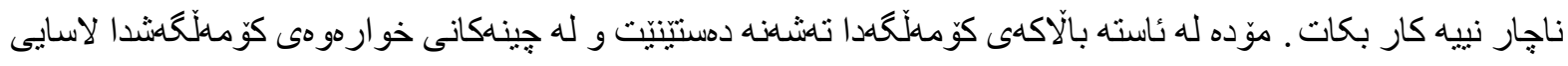

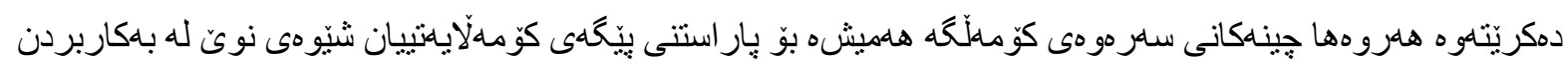

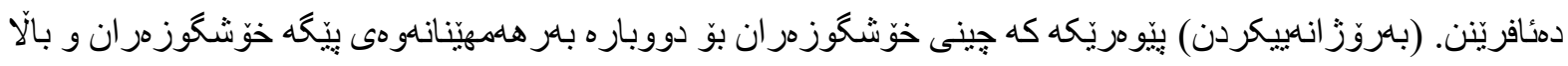

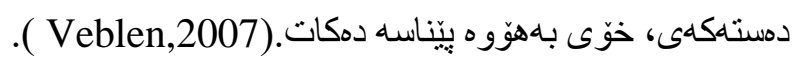

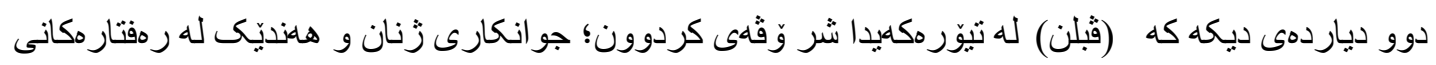

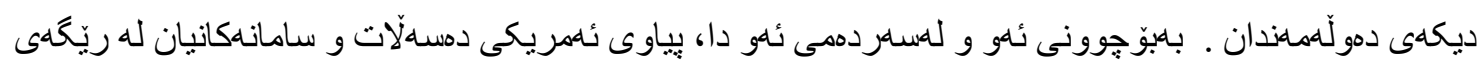

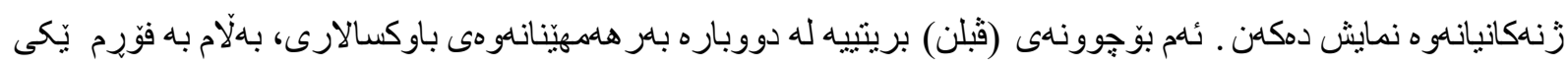

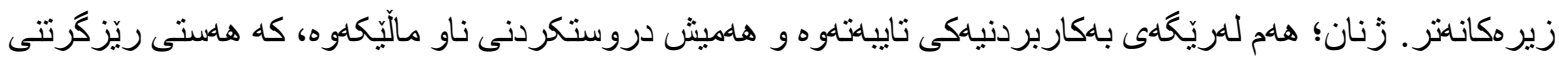

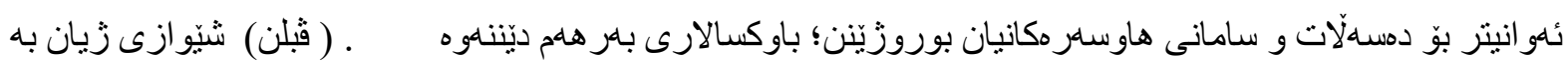

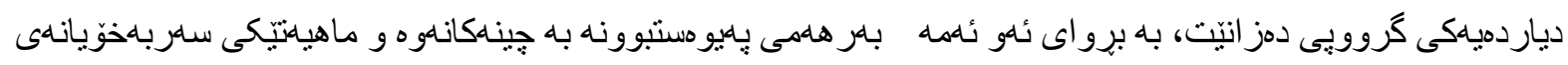

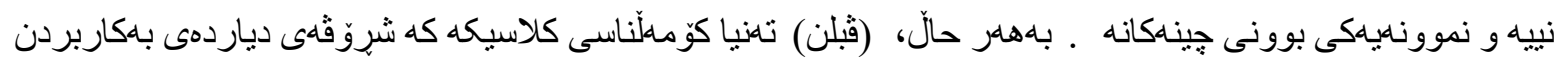

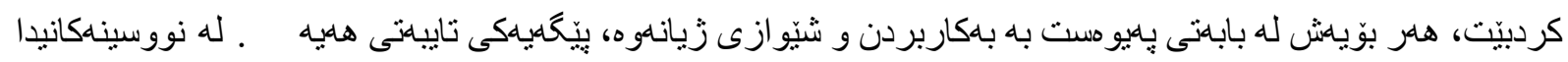

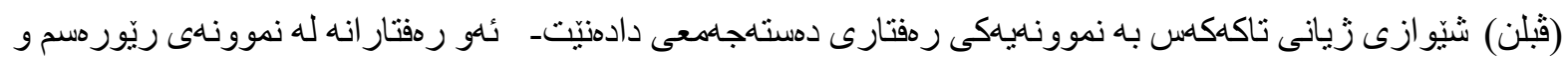

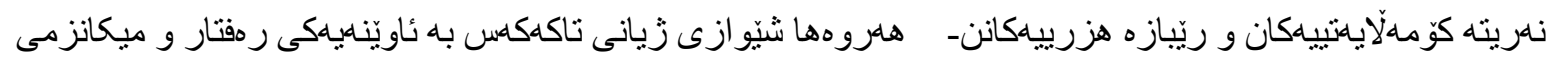

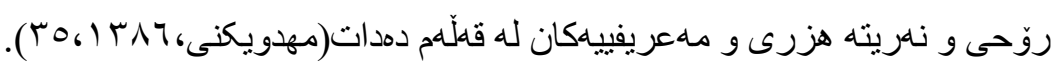

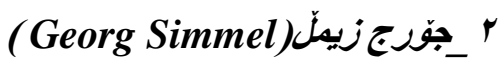

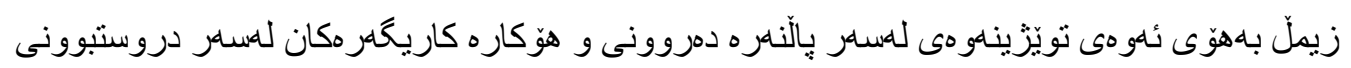

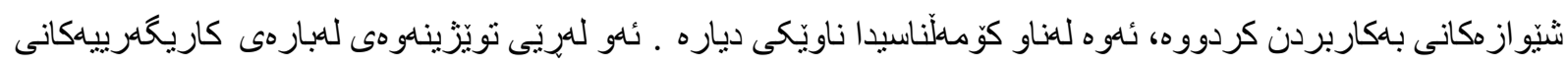

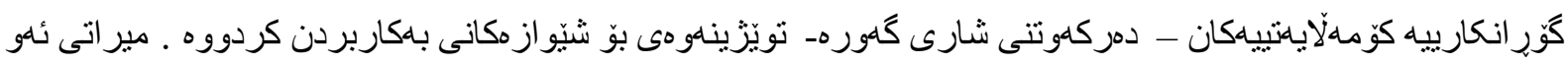

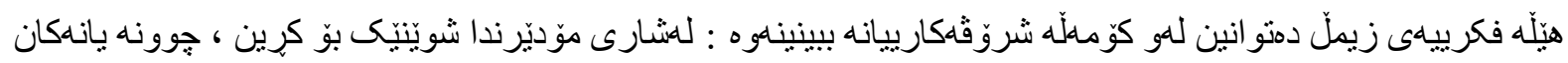

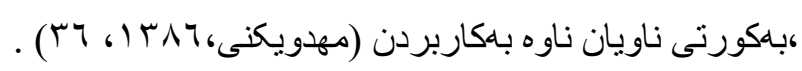

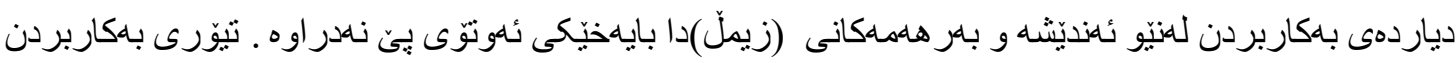

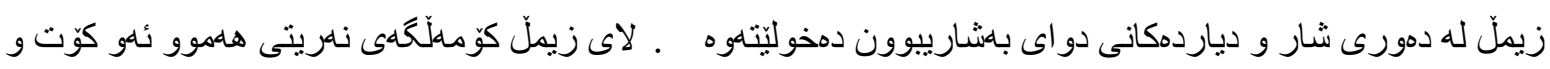

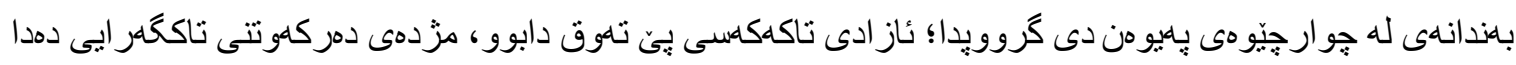

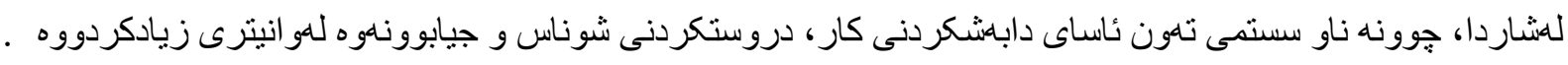

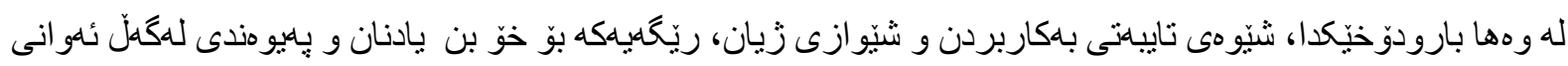




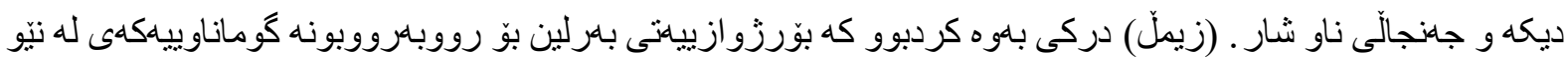

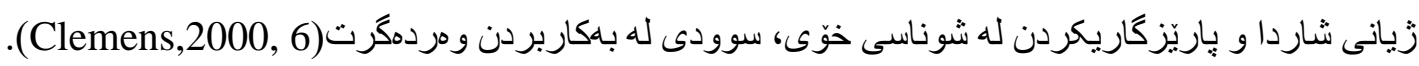

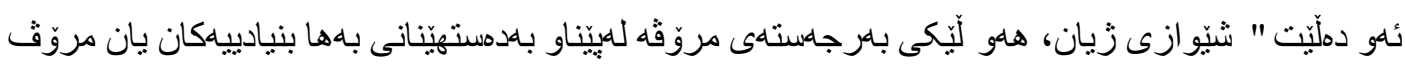

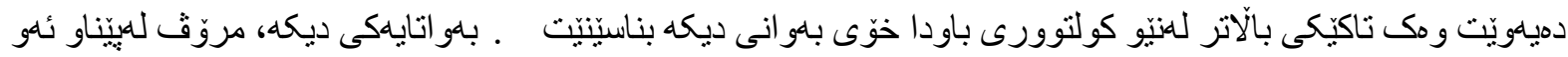

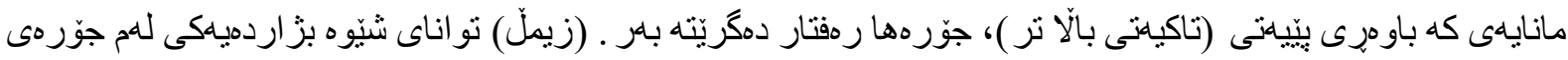

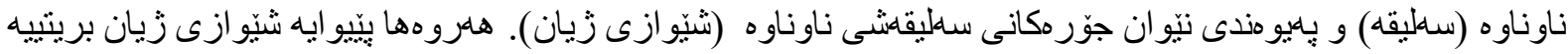

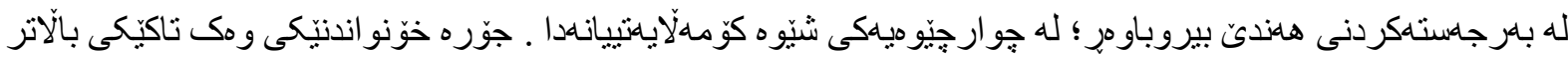

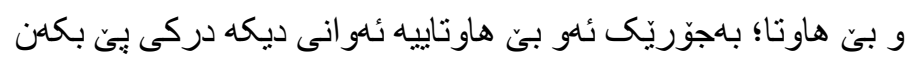

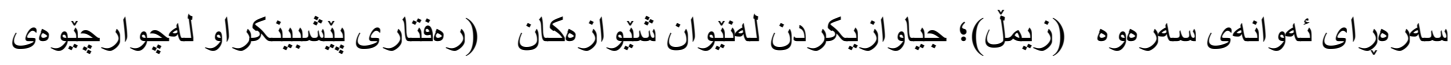

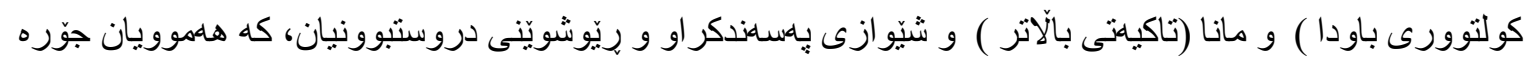

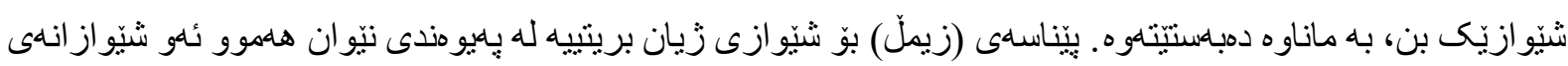

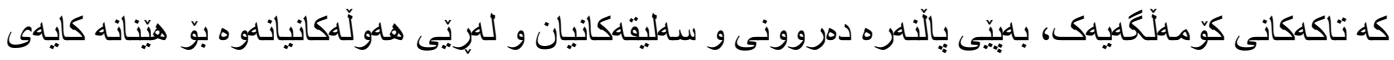

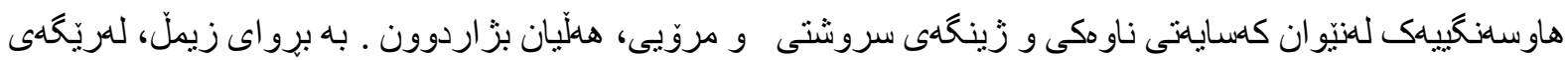

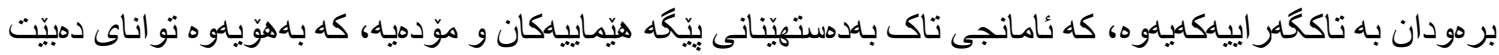

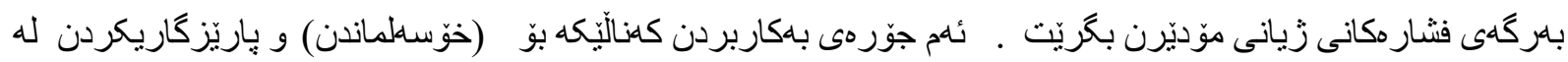

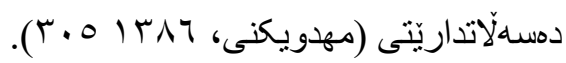

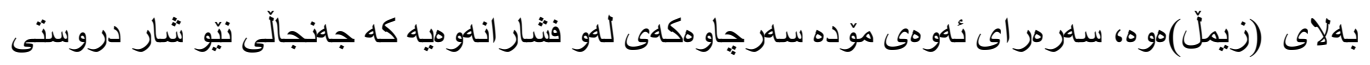

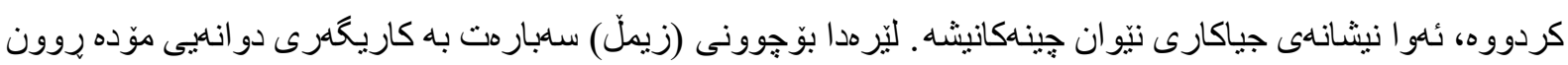

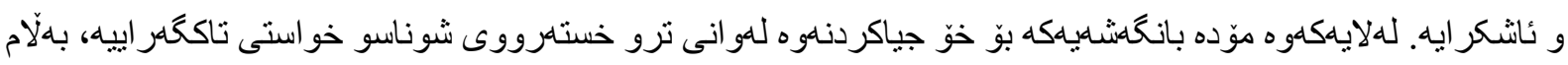

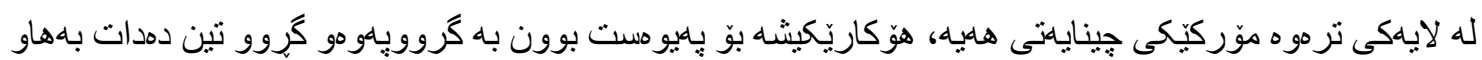

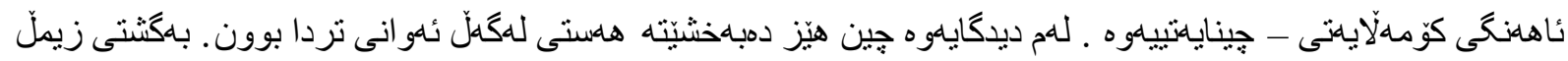

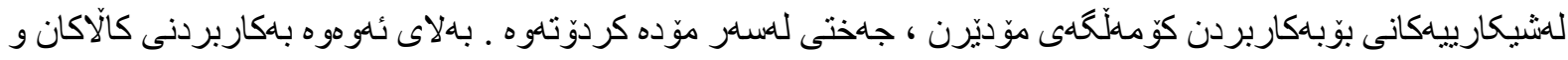

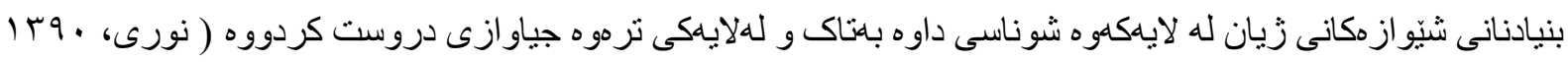

\section{Max Weber(ماكس قييهر)}

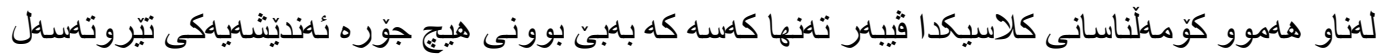

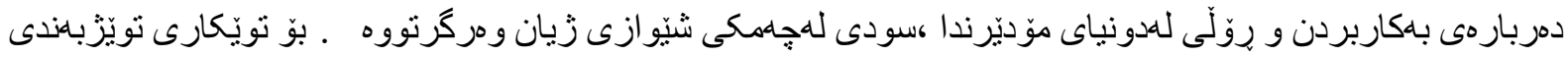

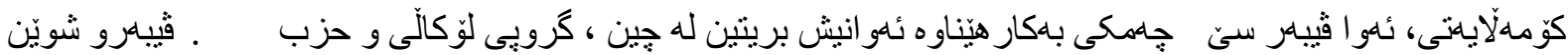

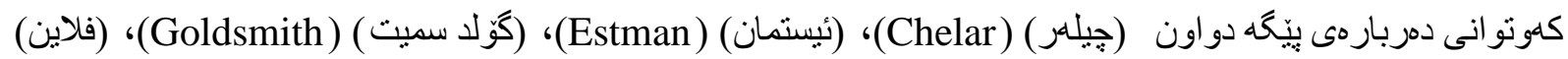
(Fline)

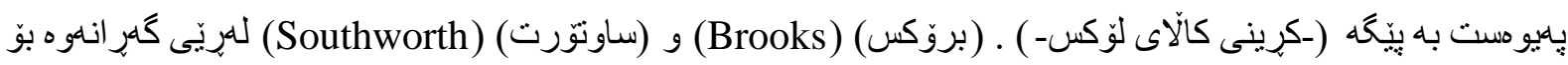

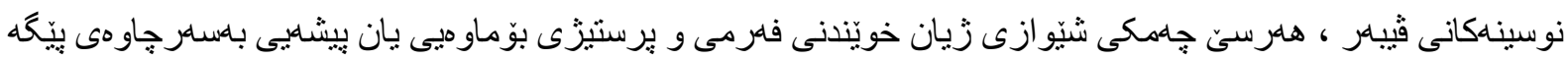




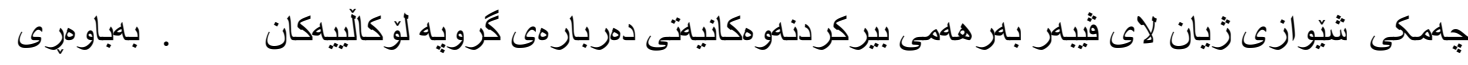

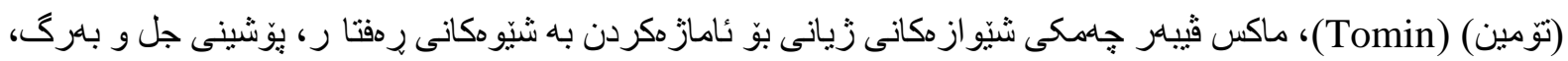

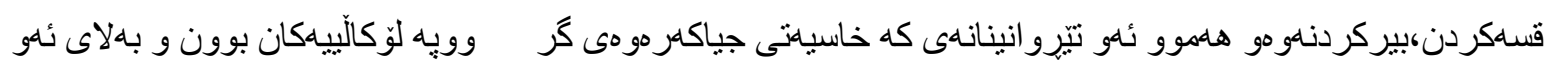

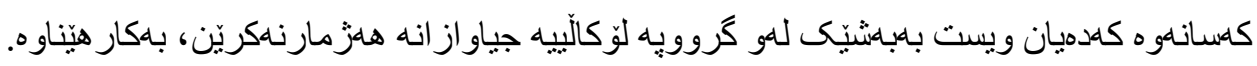

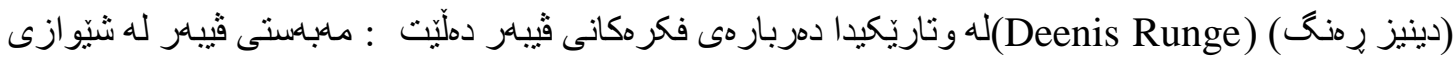

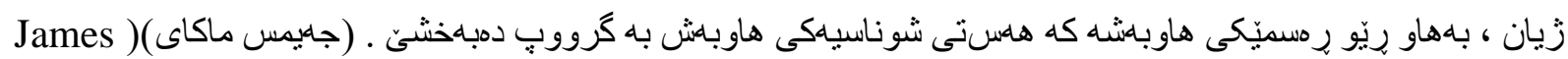

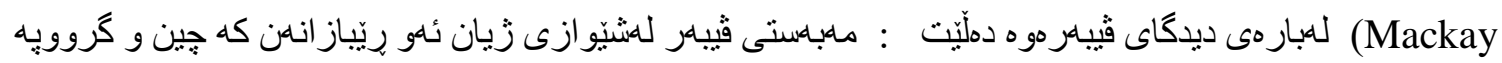

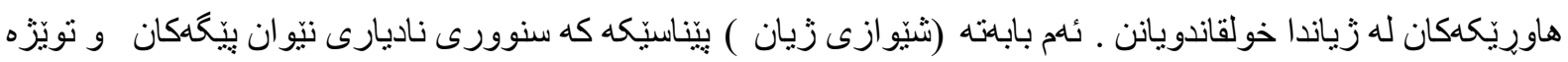

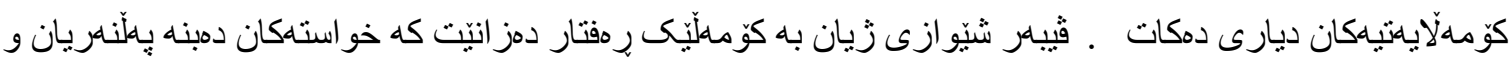

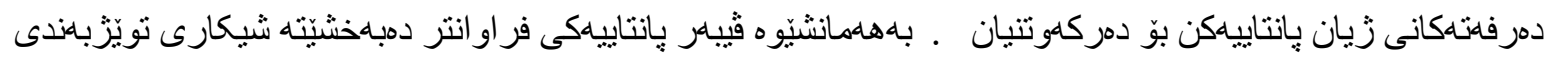

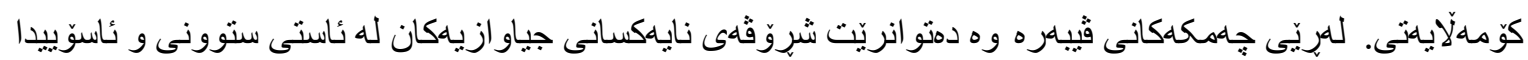

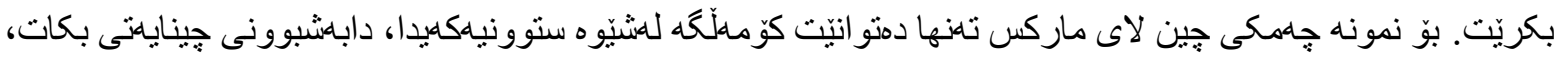

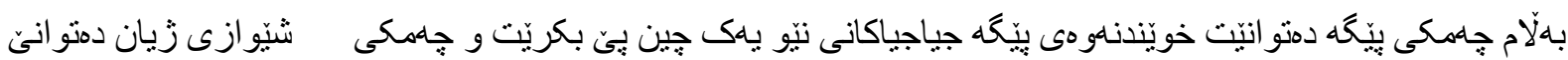

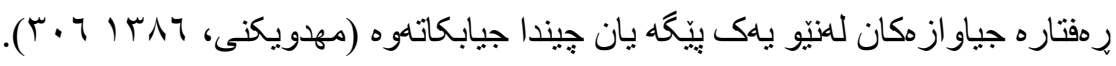

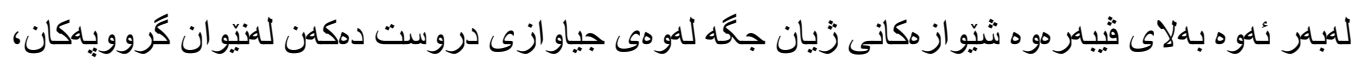

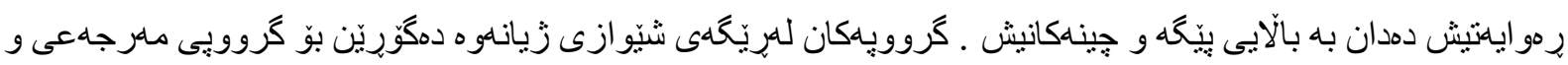

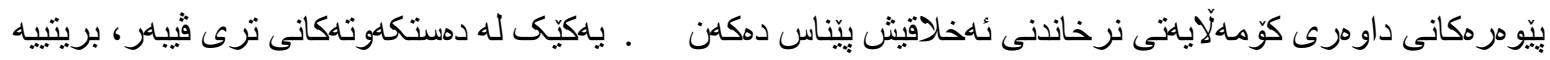

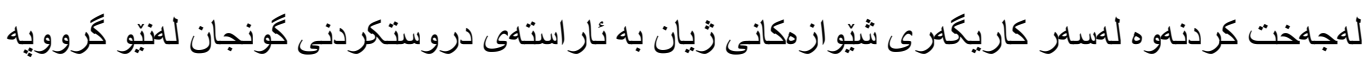

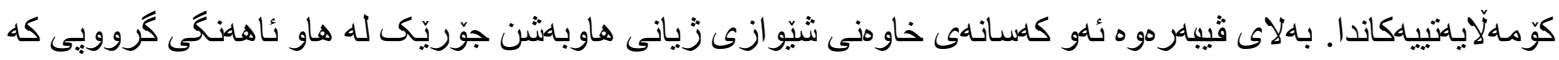

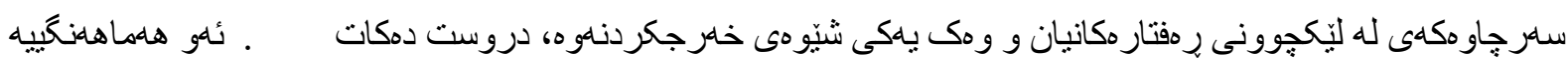

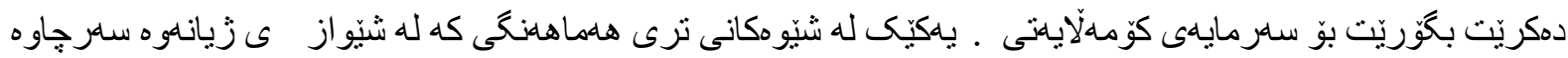

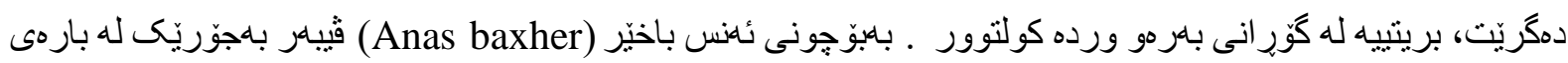

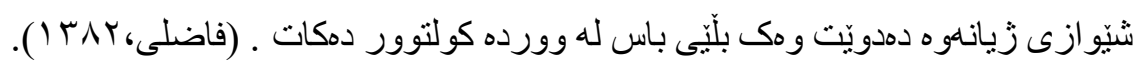

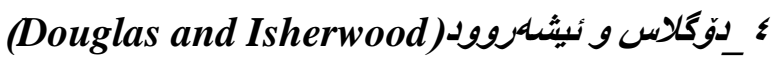

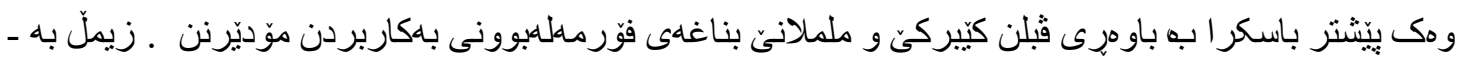

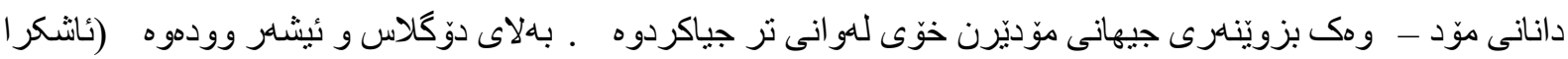

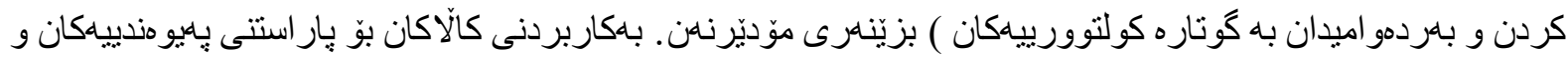

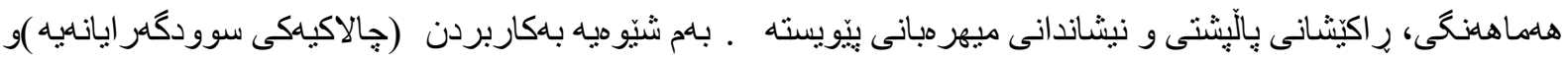

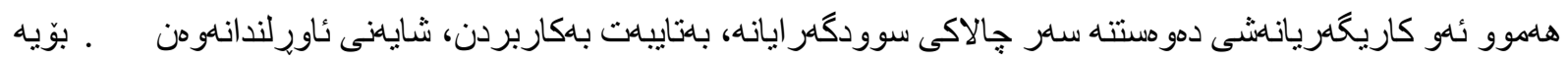

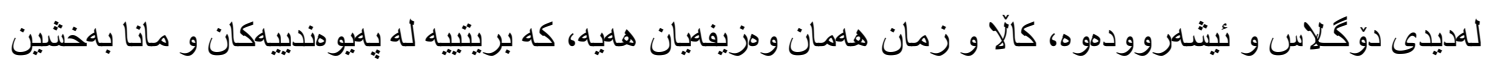

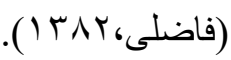

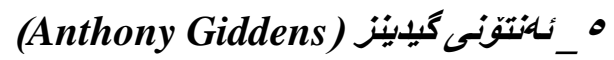




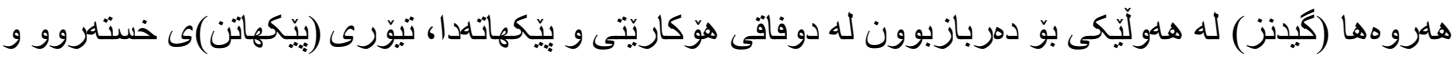

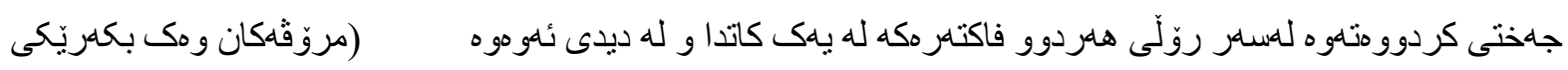

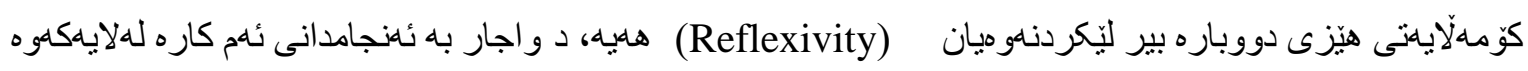

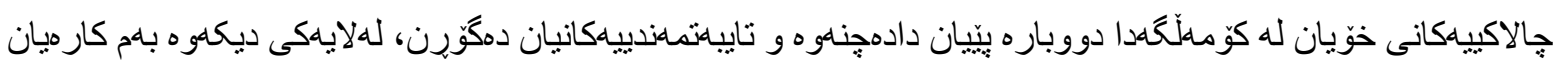

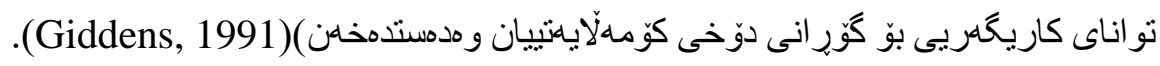

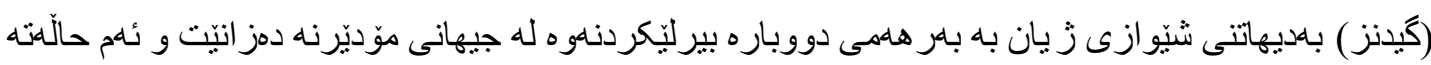

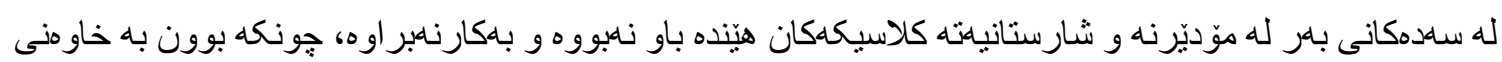

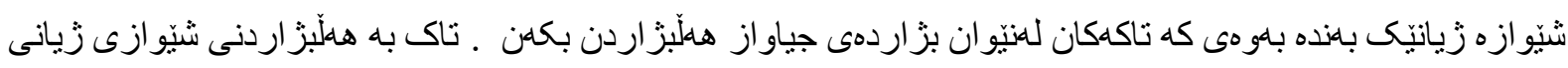

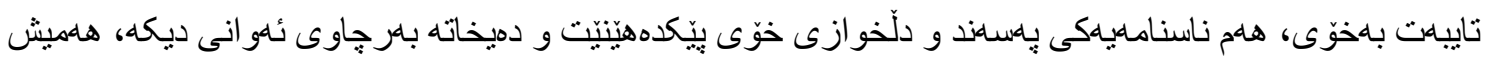

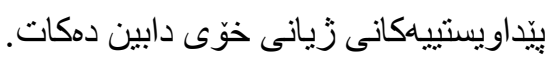

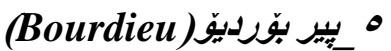

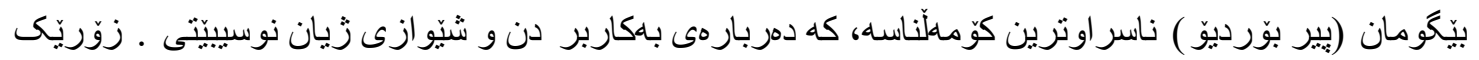

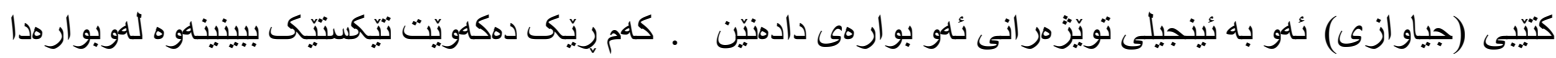

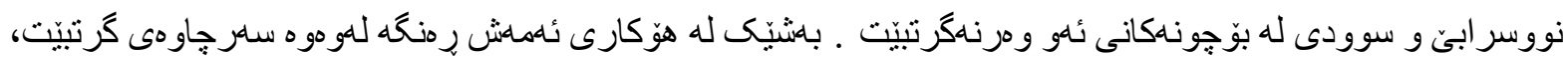

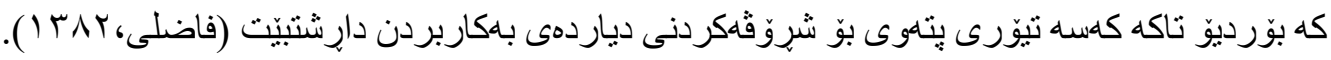

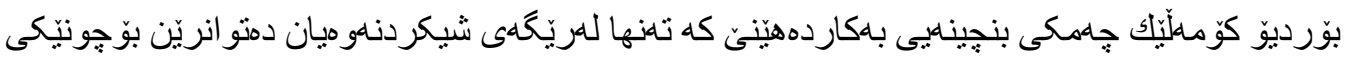

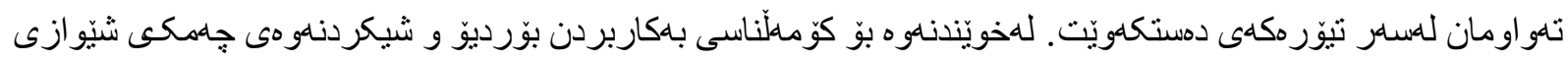

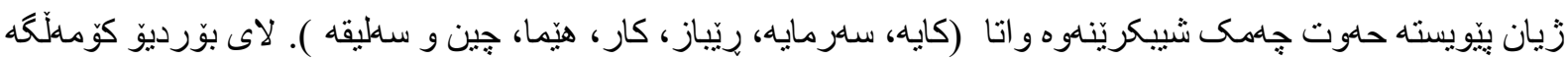

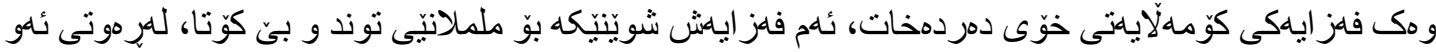

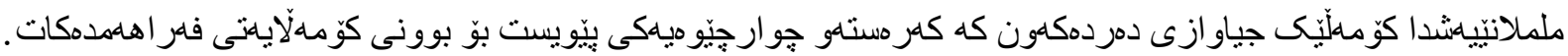

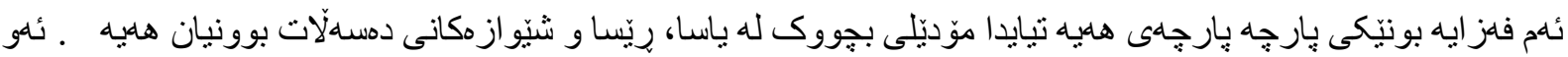

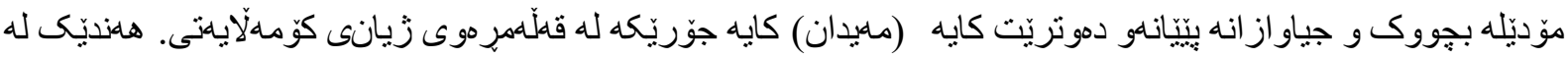

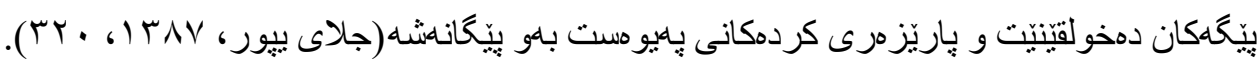

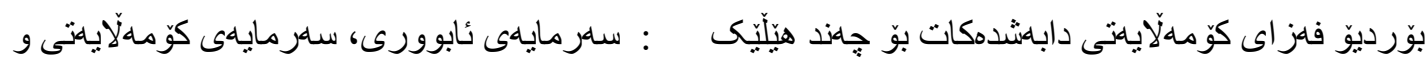

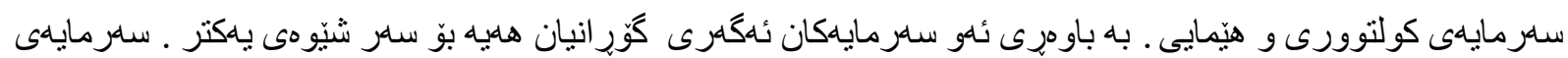

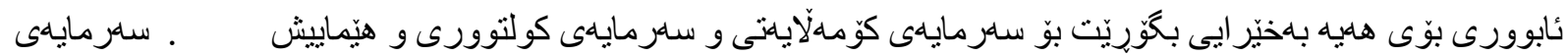

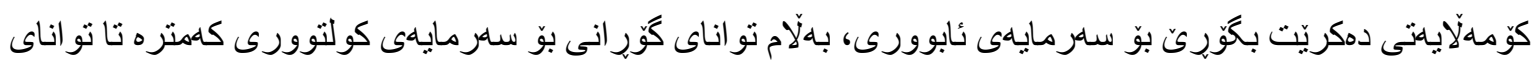

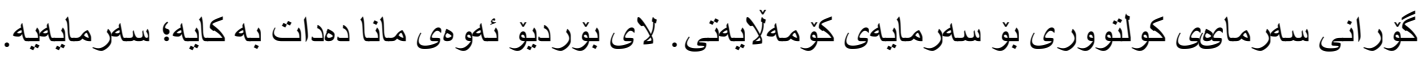

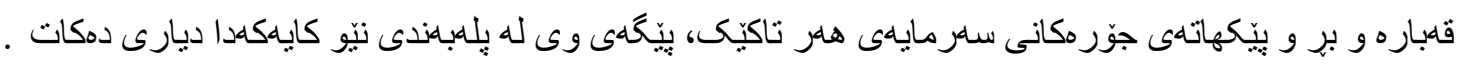

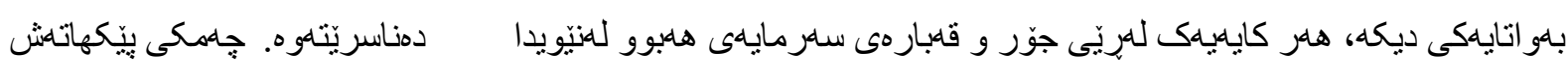

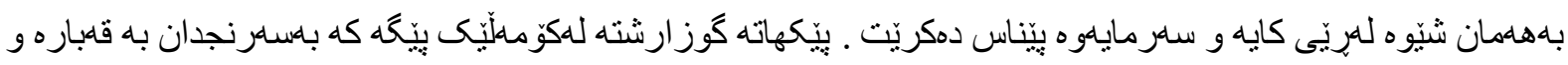

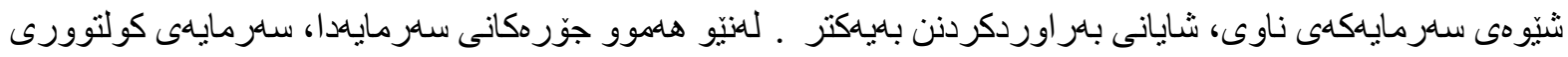

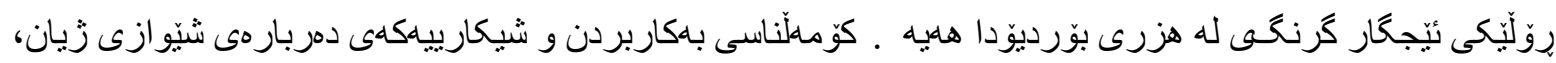




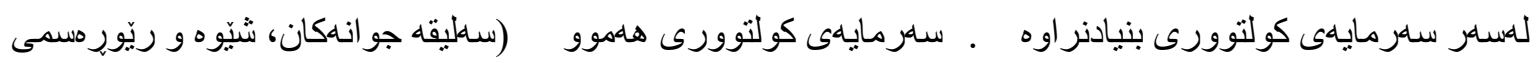

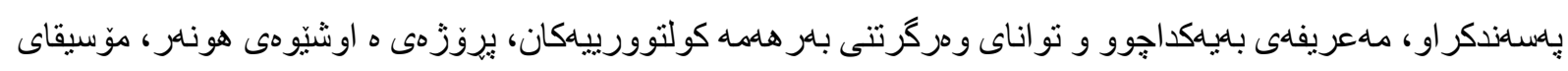

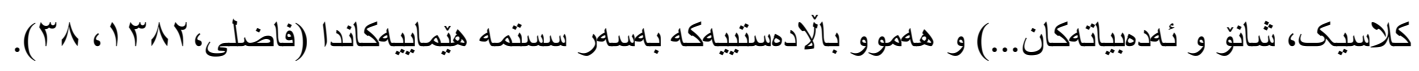

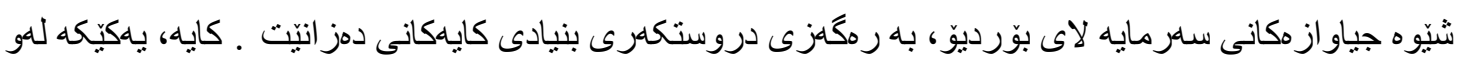

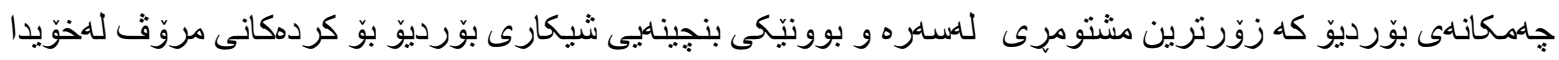

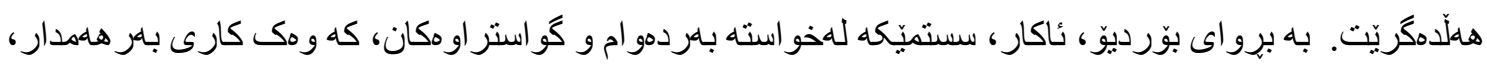

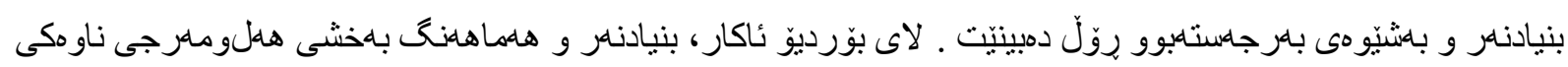

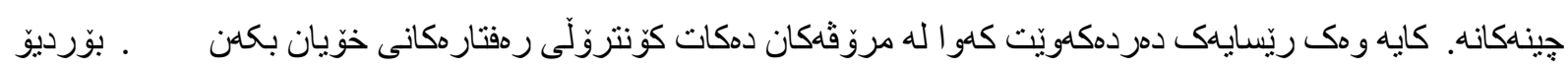

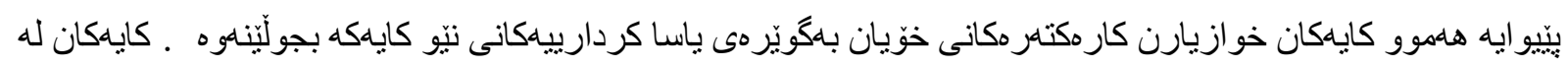

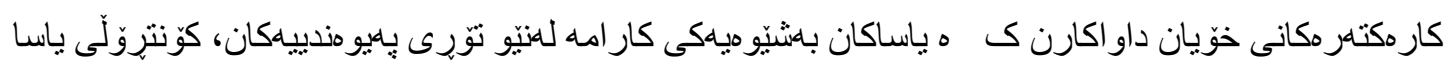

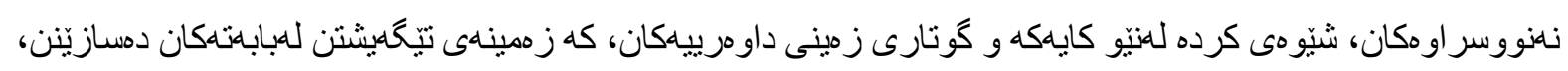

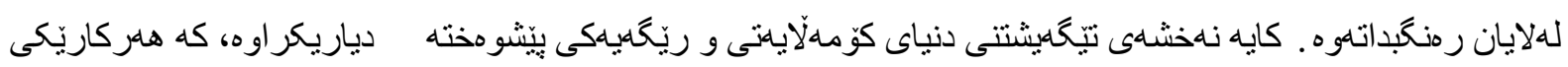

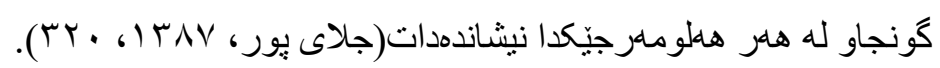

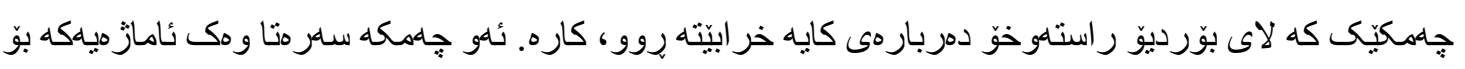

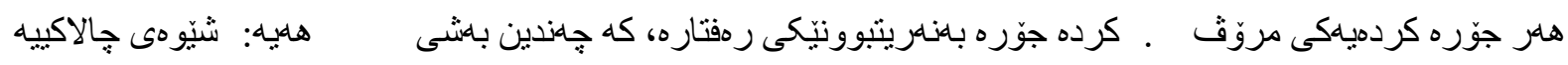

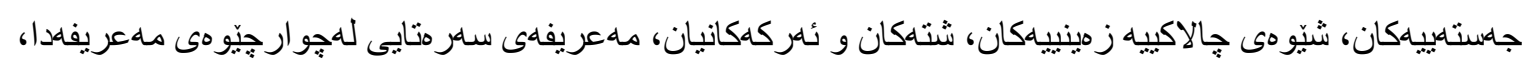

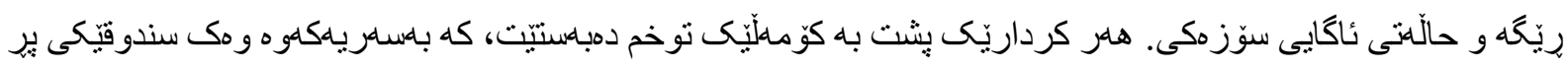

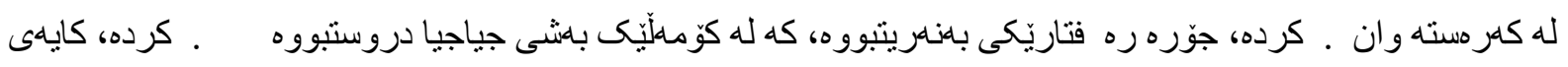

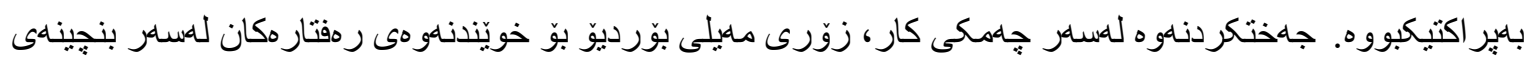

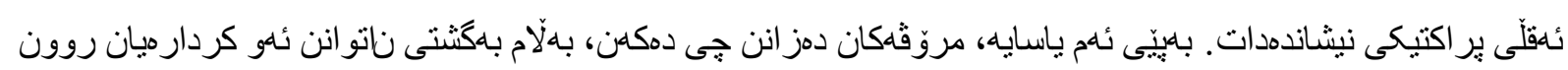

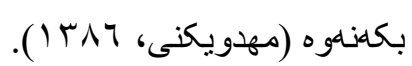

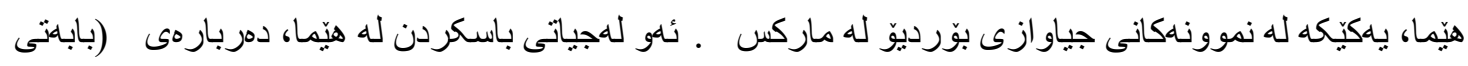

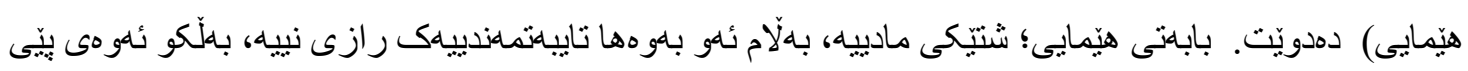

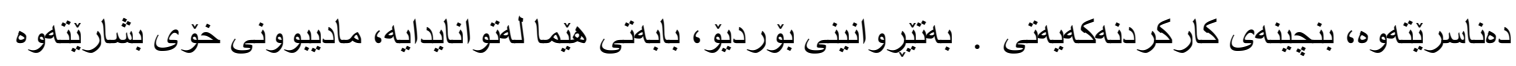

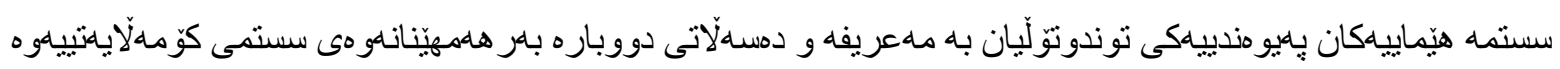

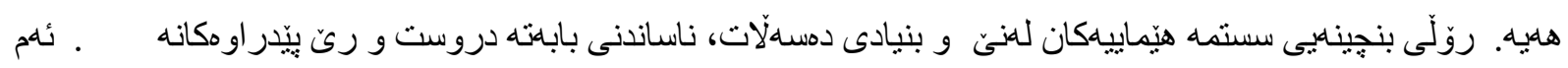

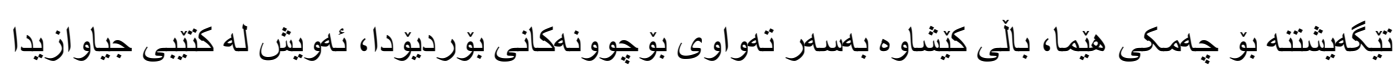

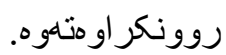

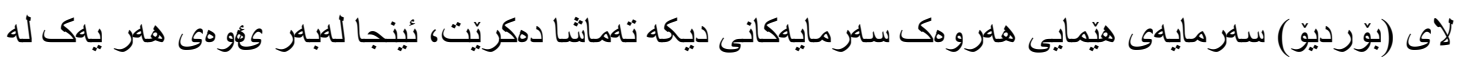

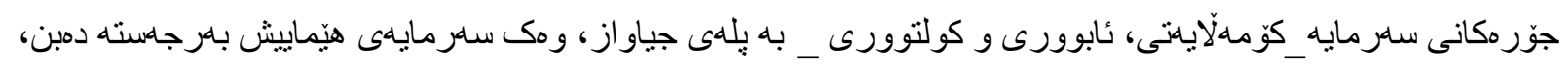

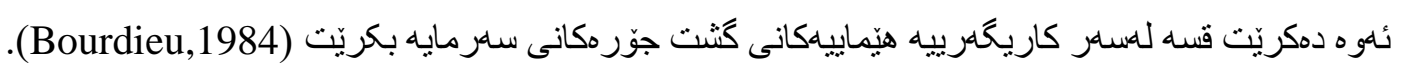

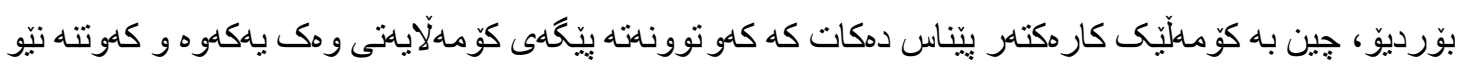

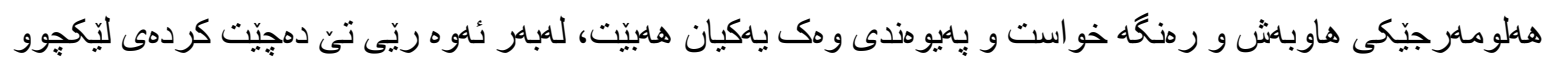




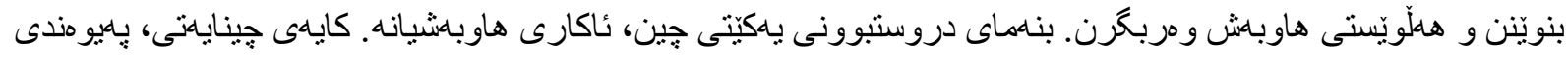

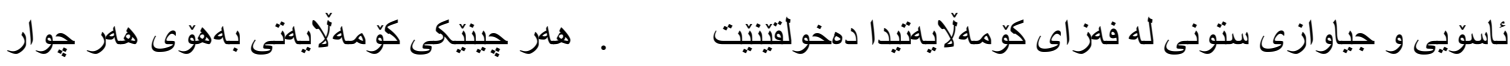

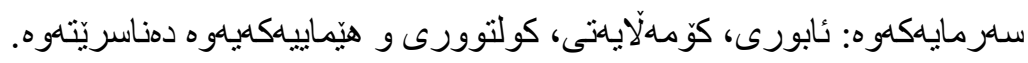

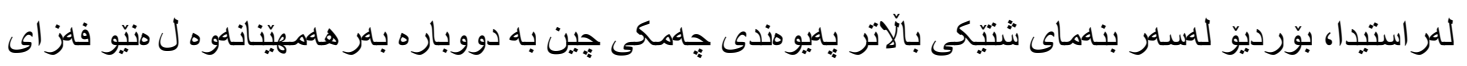

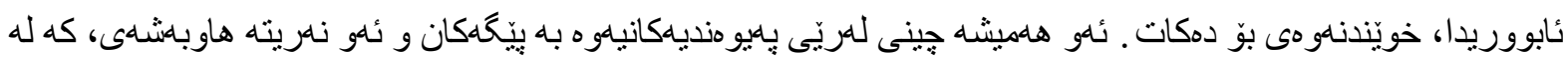

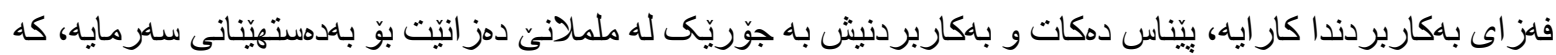
له فورمدلهكردنى جِيندا رِوّلّى هليه.

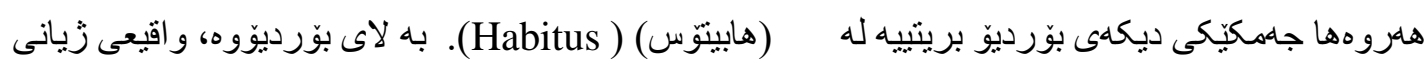

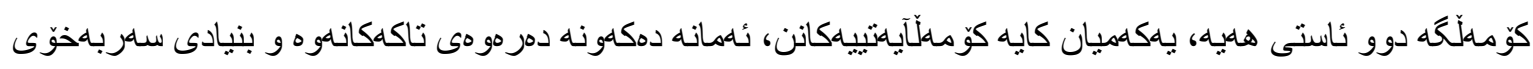

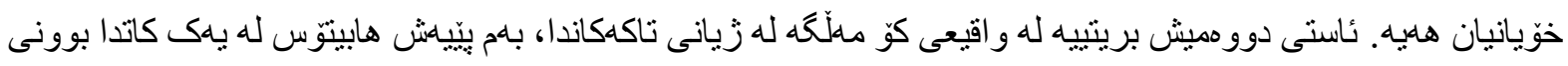

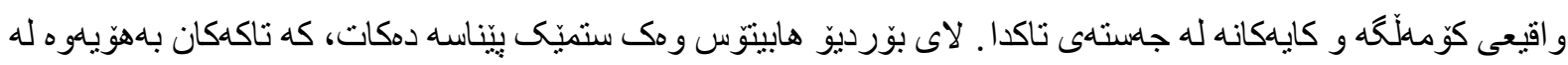

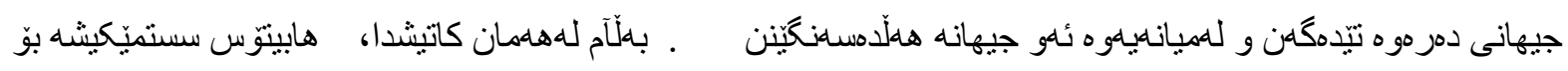

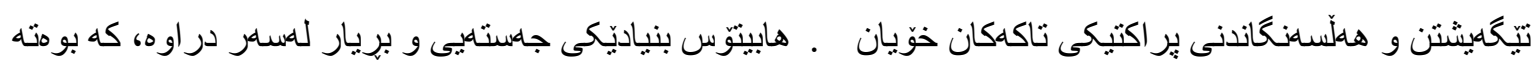

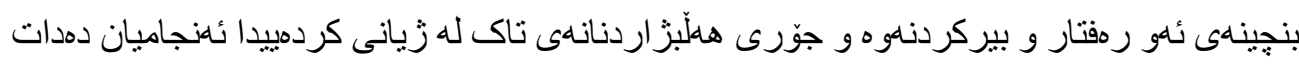

(Bourdieu,1984)

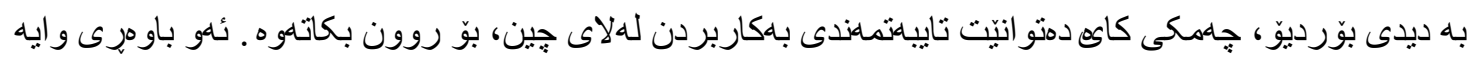

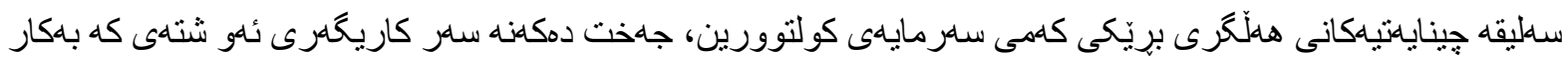

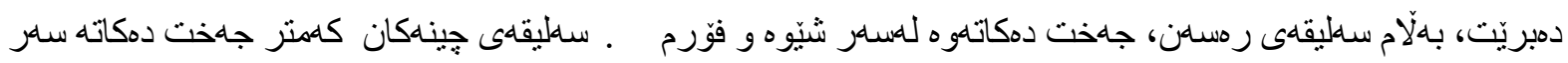

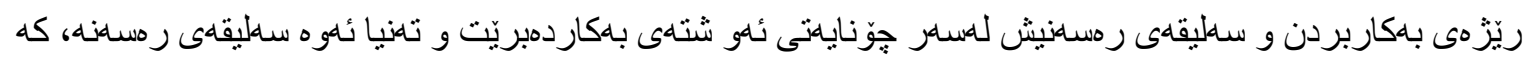

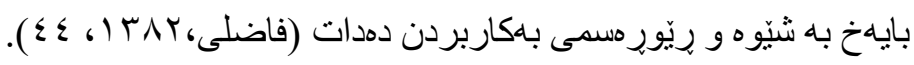

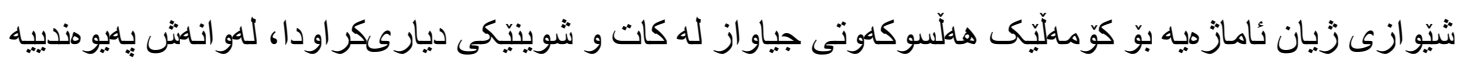

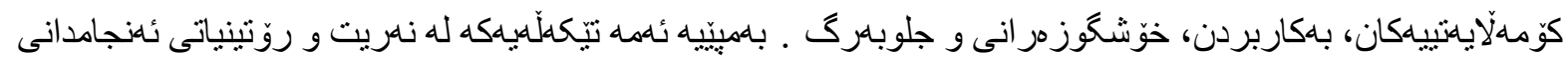

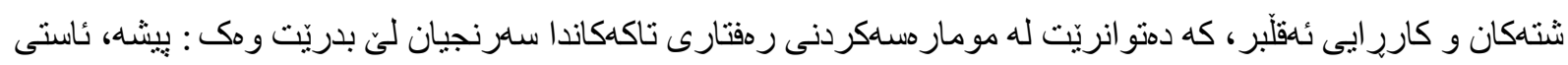

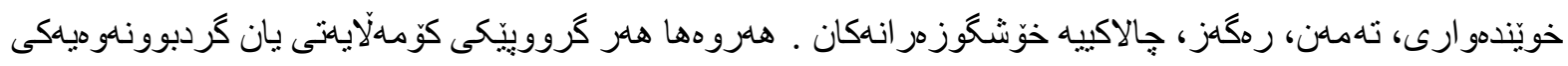

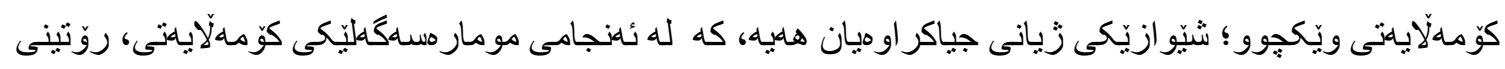

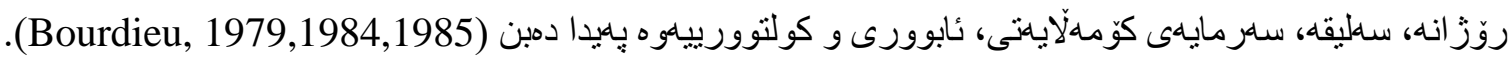

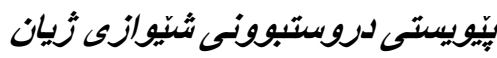

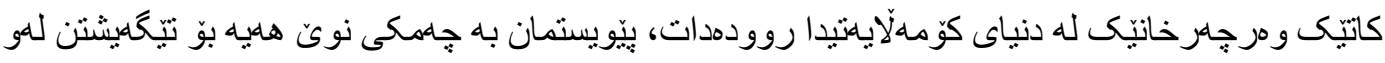

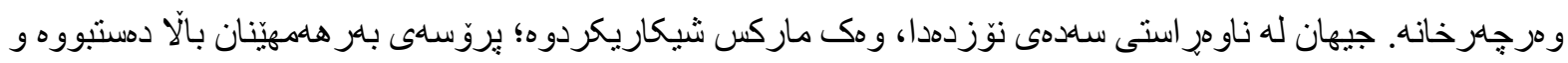

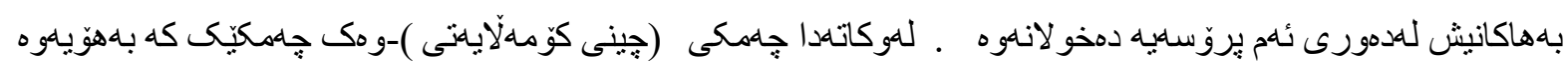

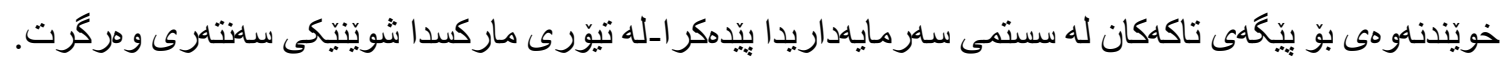

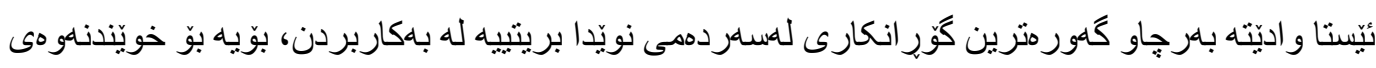

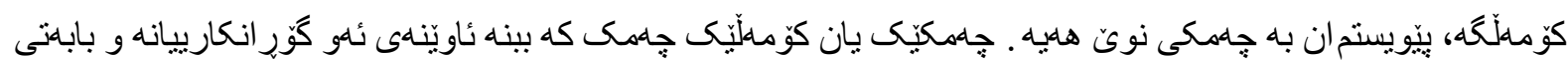




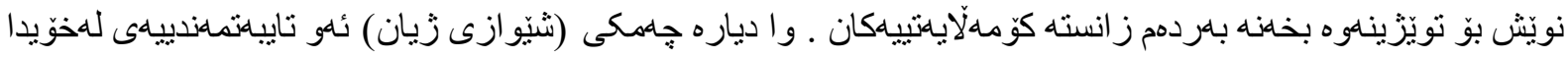

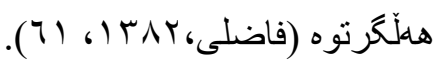

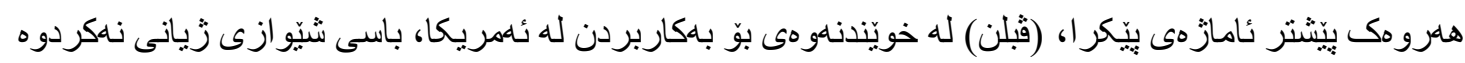

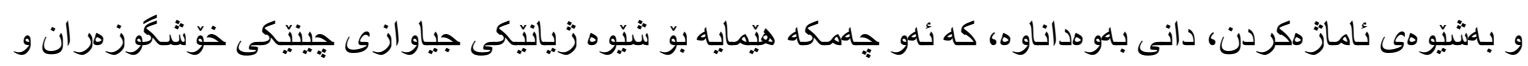

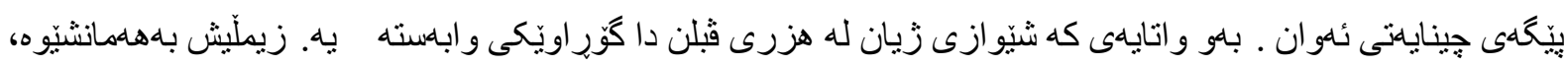

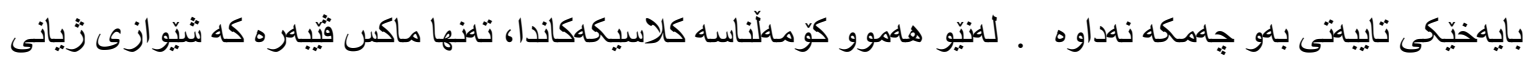

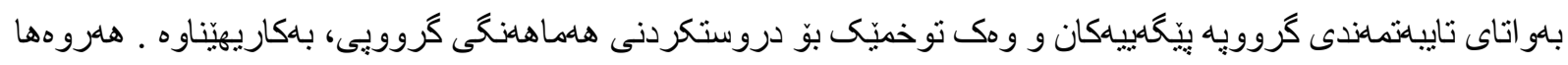

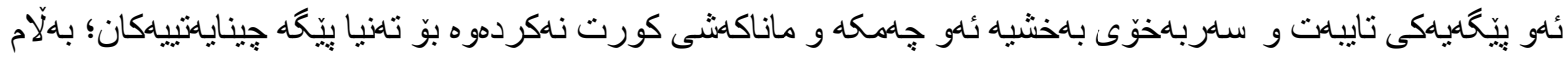

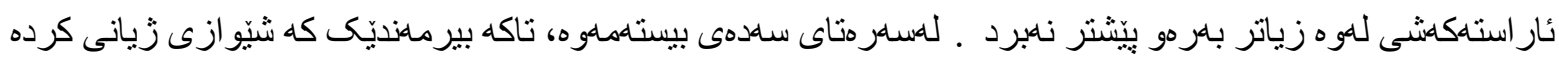

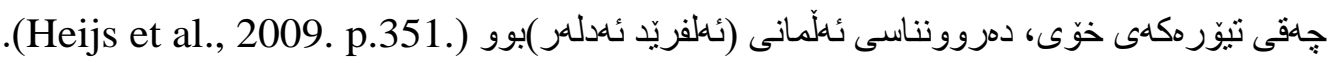

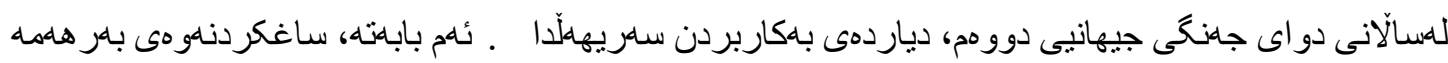

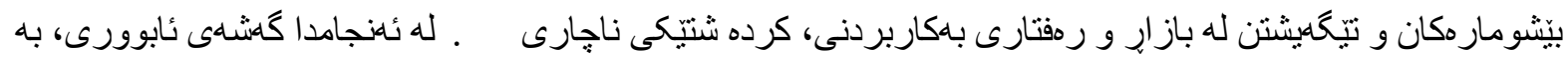

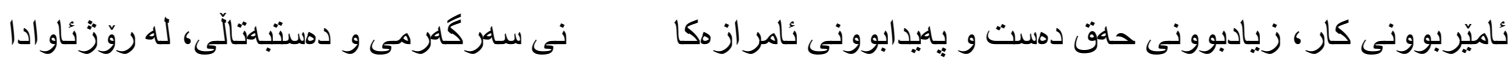

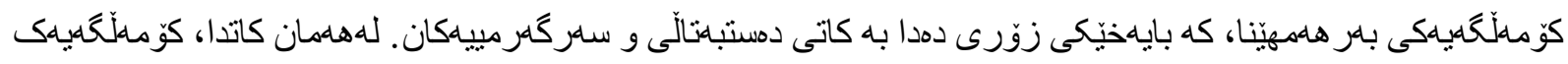

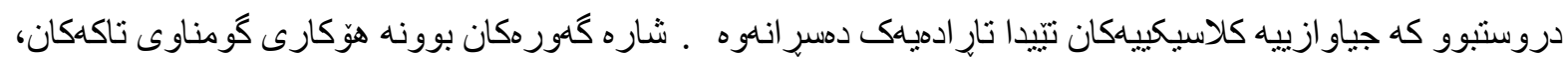

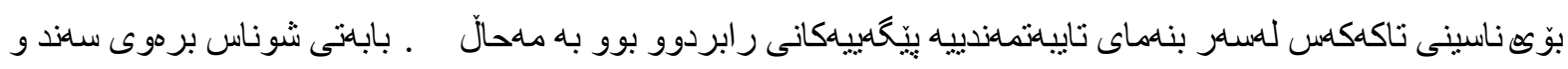

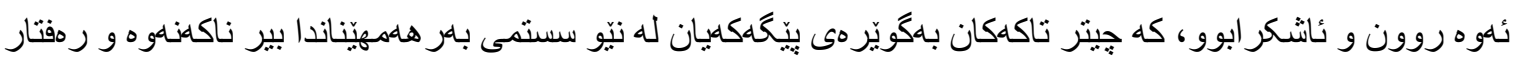

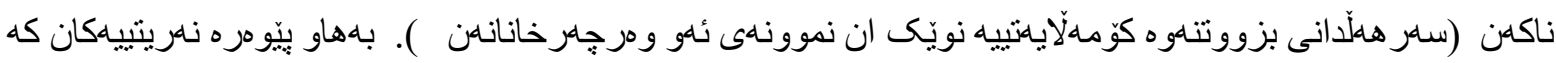

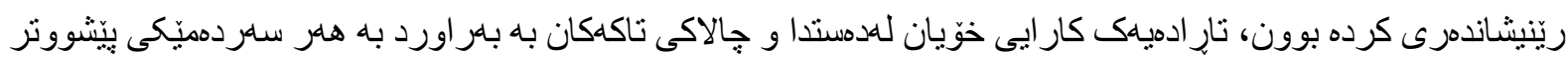

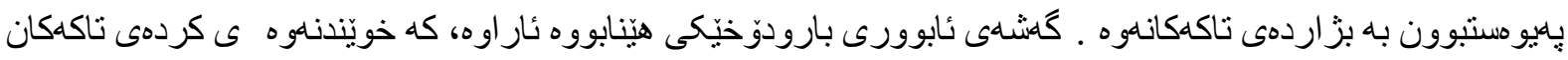

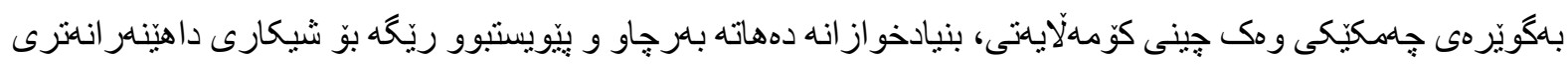

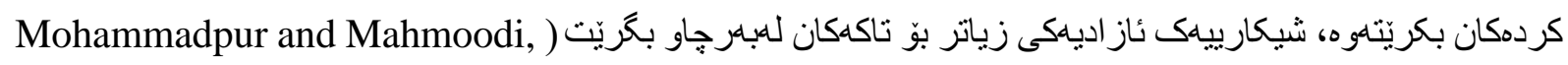

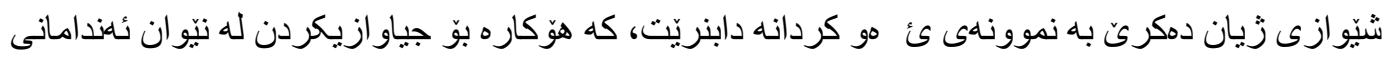

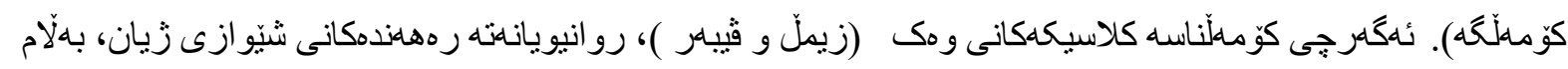

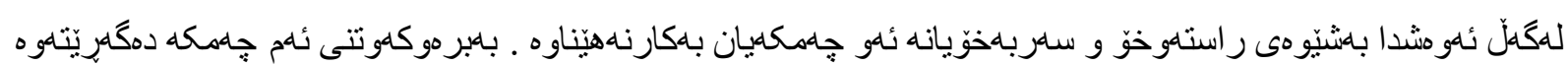

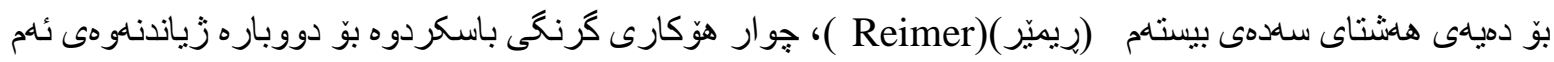

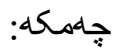

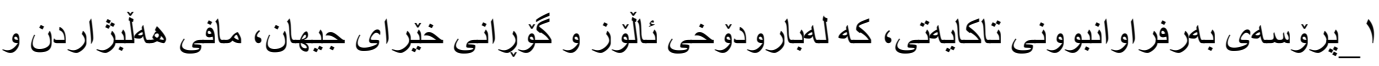

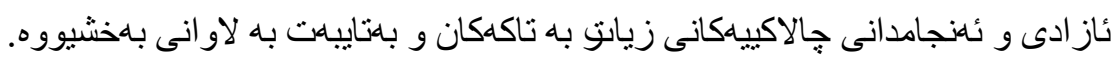

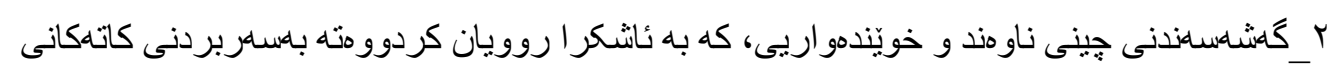

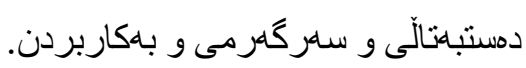




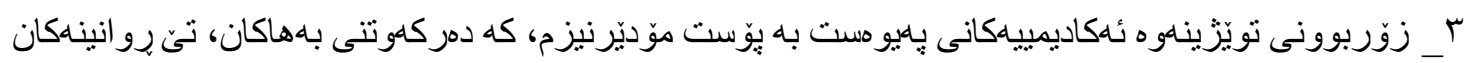

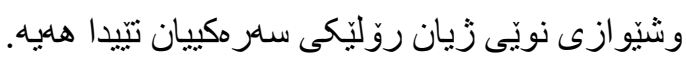

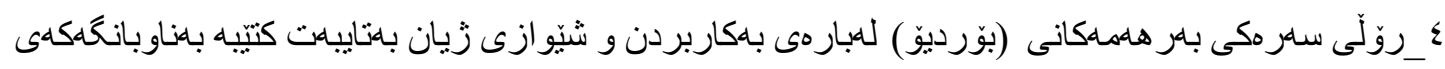

(جياوازى)(Reimer,1995)

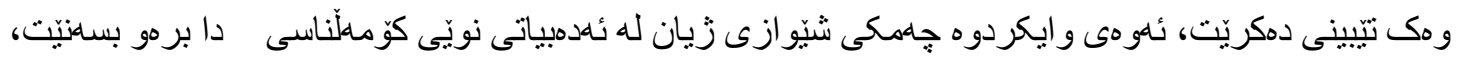

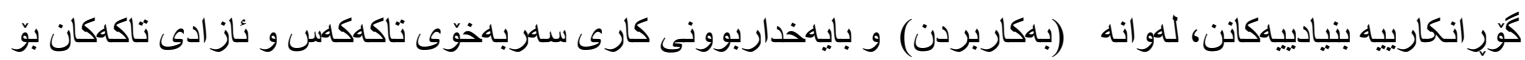

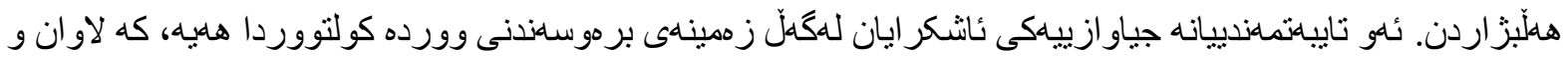

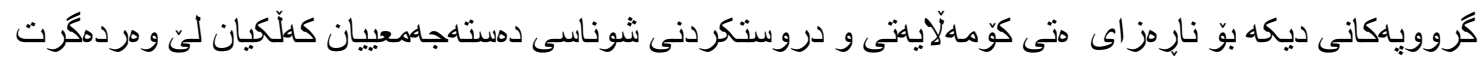

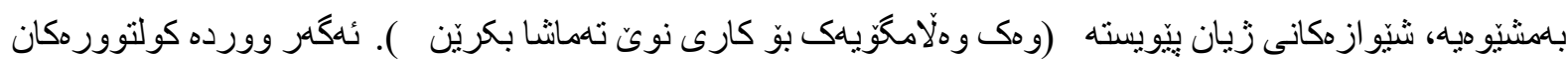

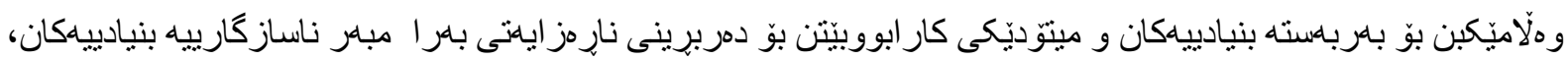

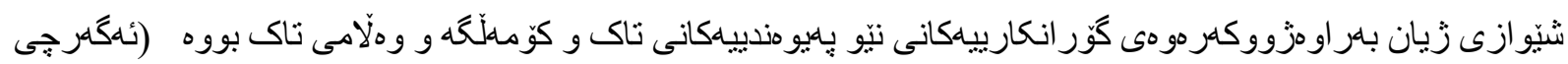

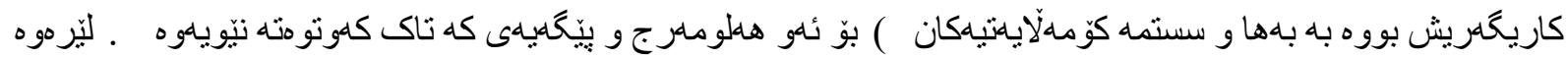

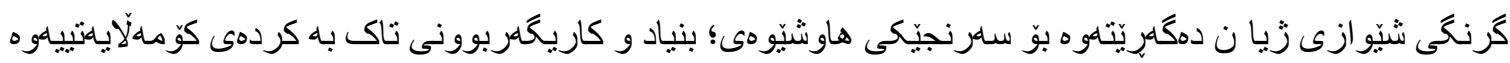

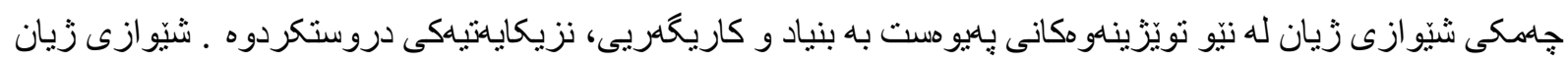

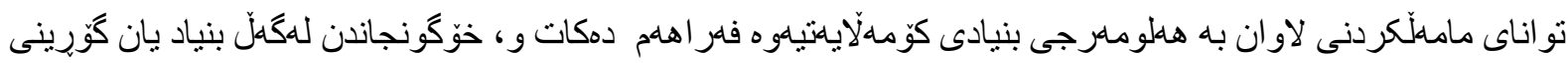

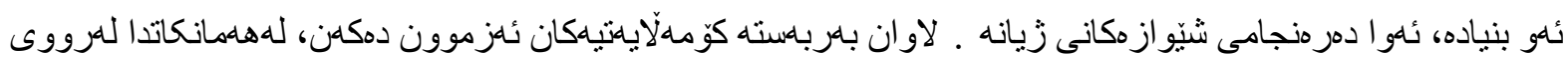

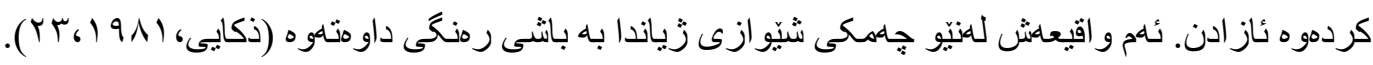

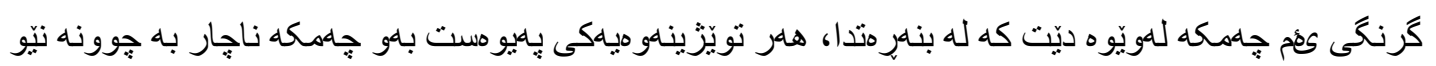

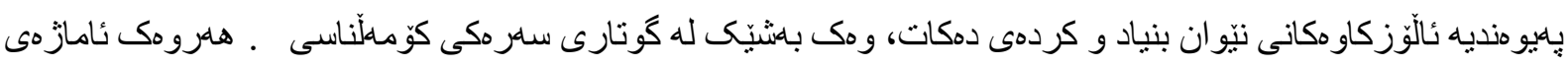

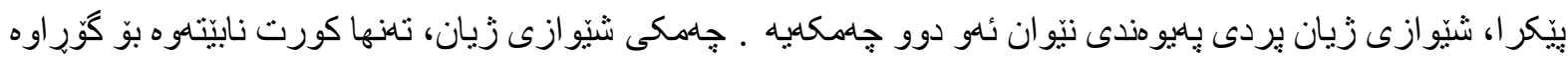

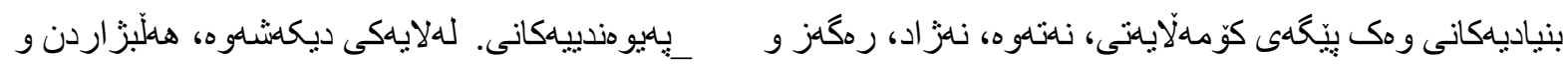

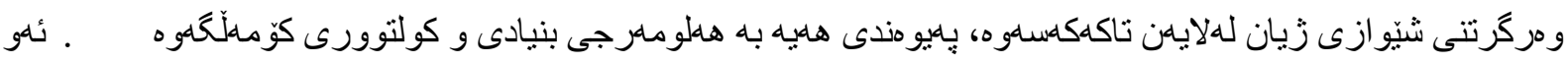

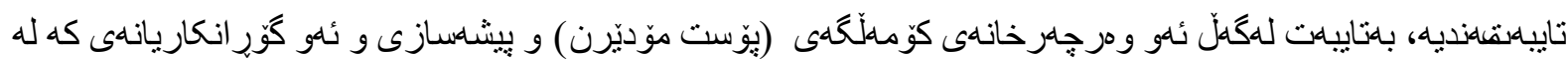

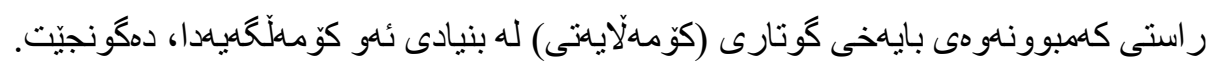

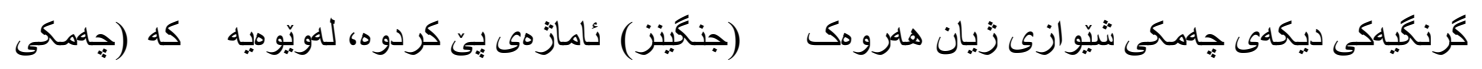

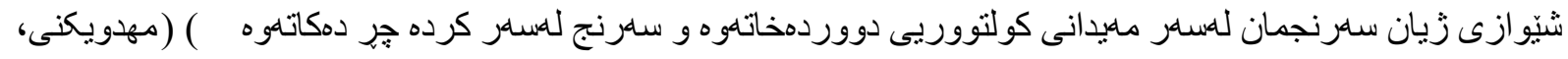

. (I) TMT

\section{بِيناسهى شيَيوازى ثريان}

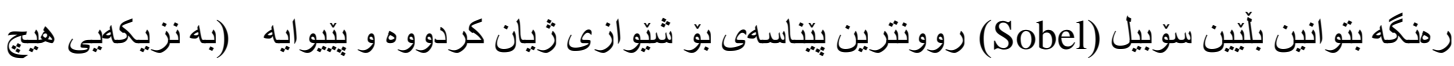

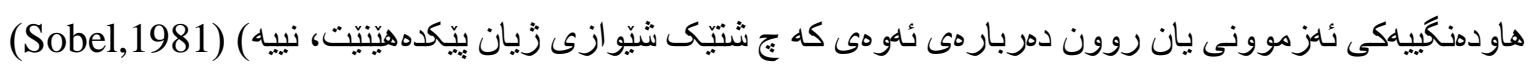

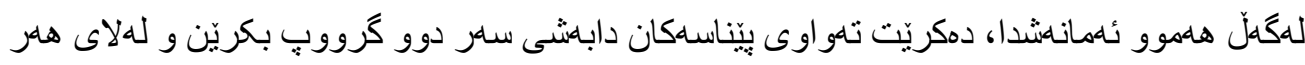

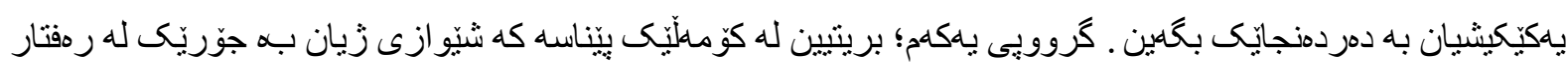

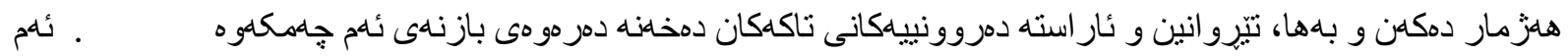




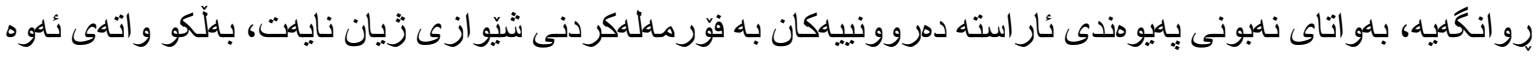

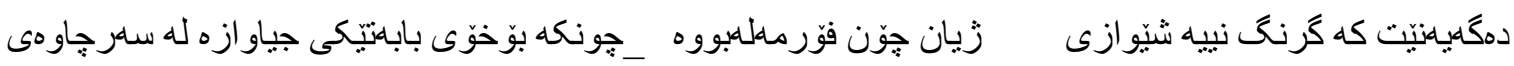

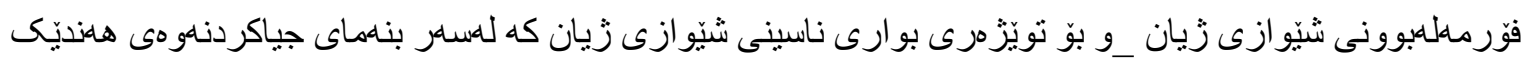

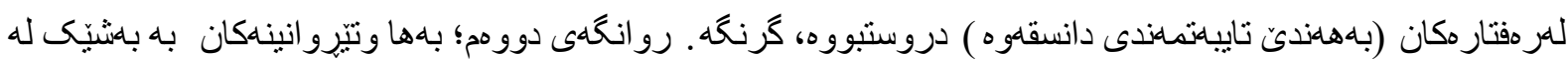

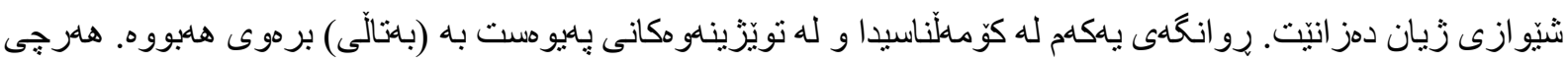

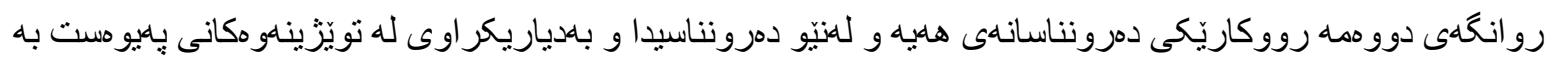

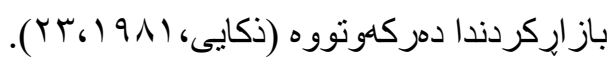

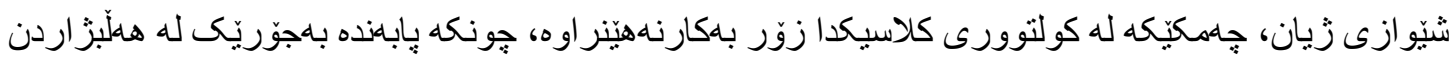

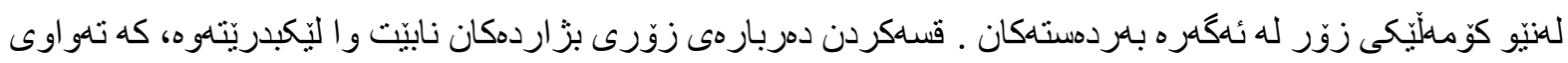

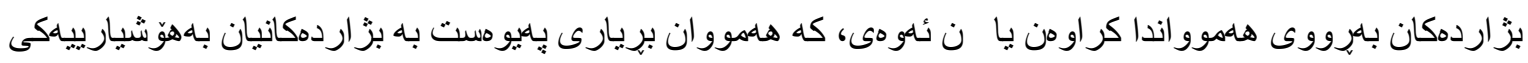

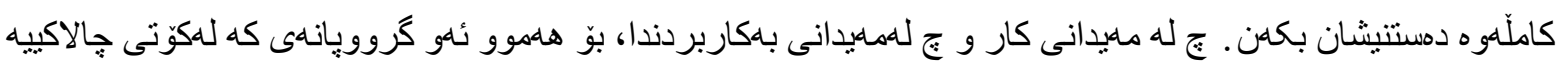

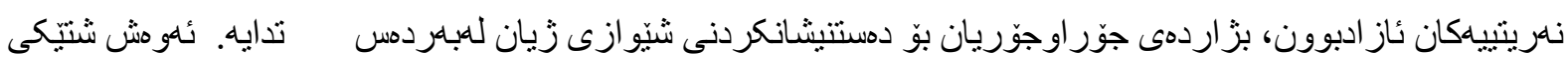

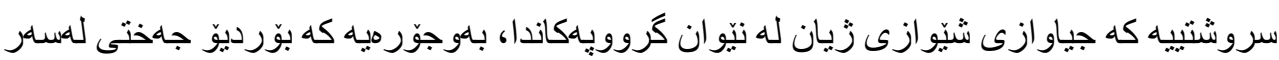

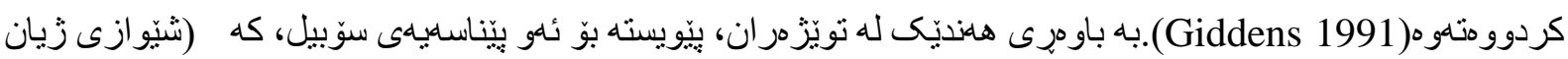

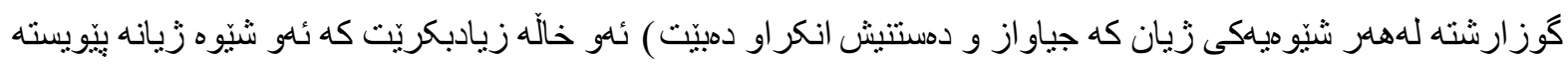

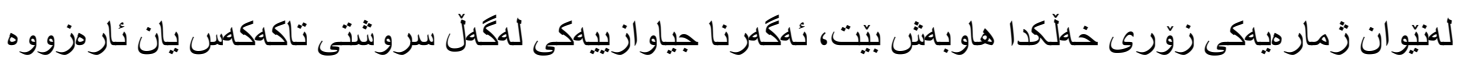
بهكاربردنيهكانى تاكهكسدا نابيّت. هين و شنيوازى ثيان

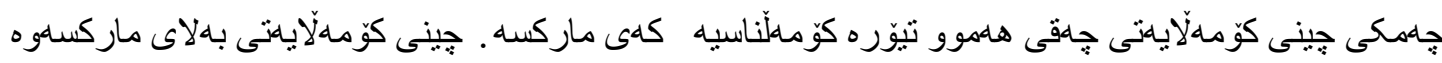

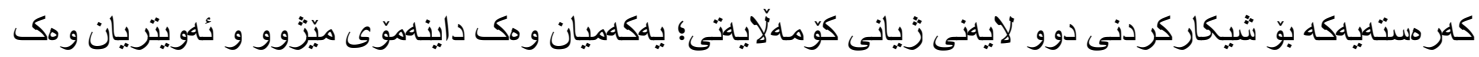

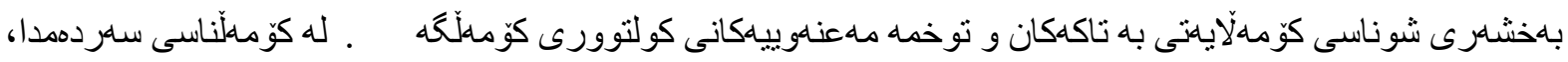

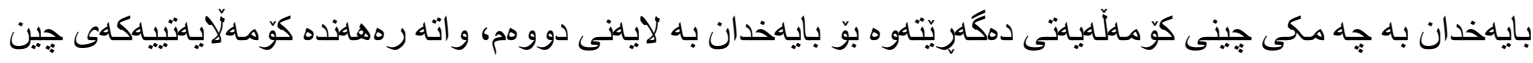

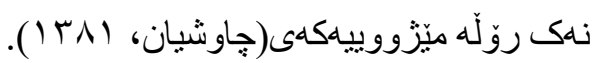

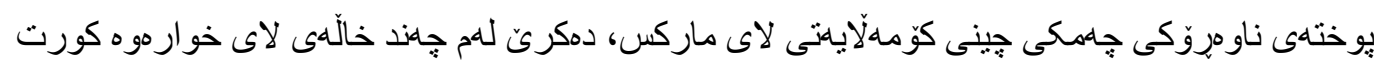

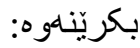

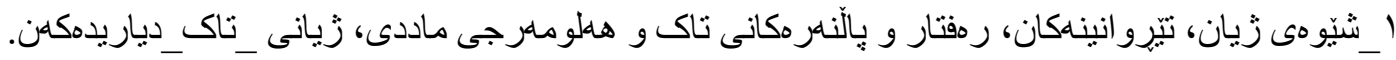

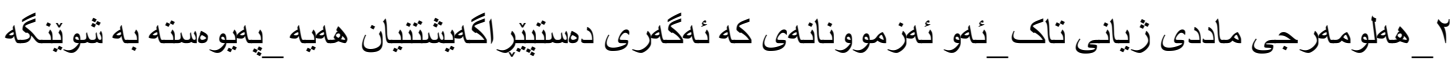

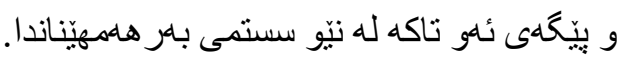

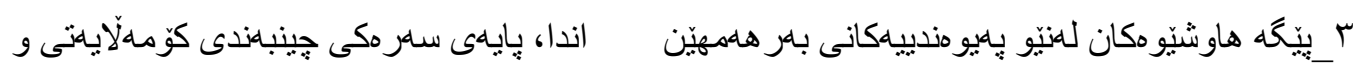
فوّرمالمبوونى شوناسى كوّمالَّايهنييه.

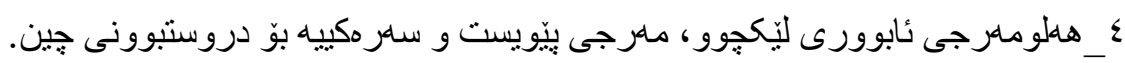

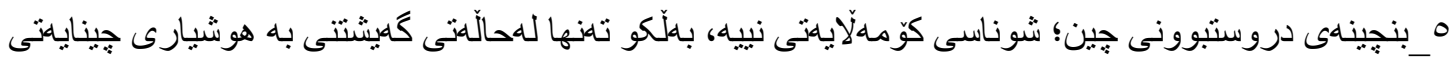

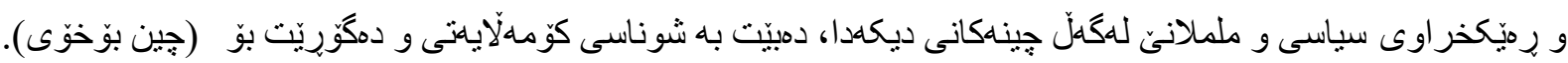




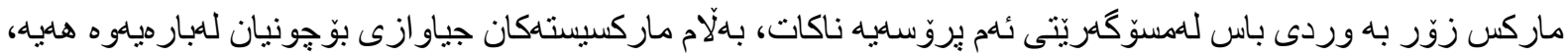

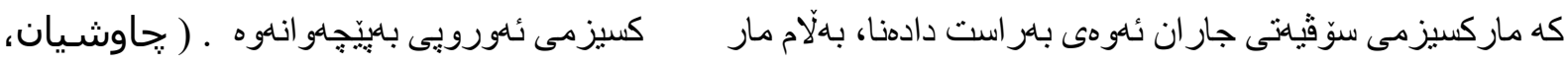

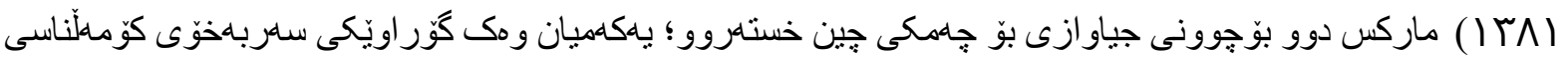

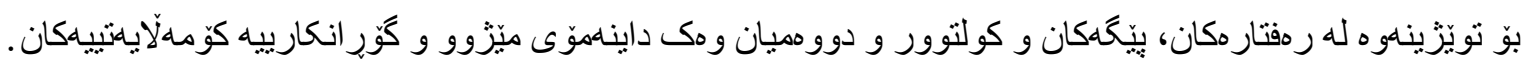

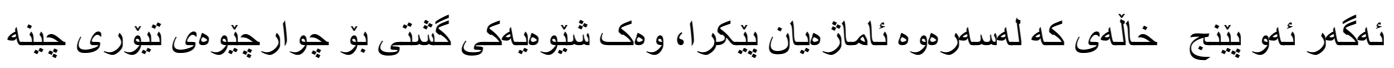

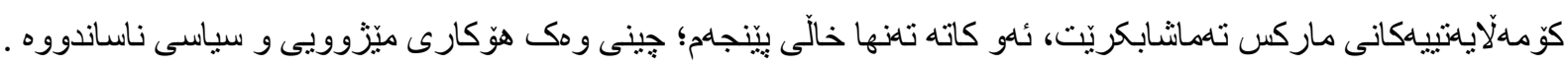

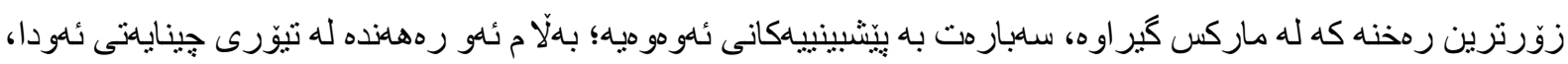

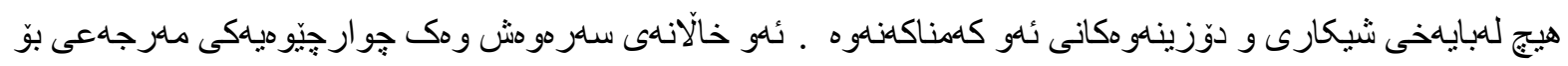

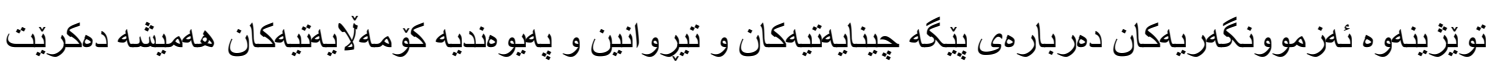

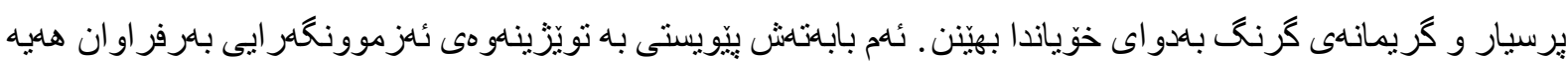

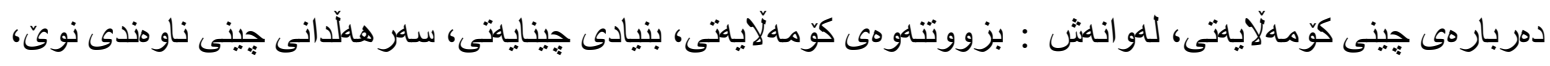

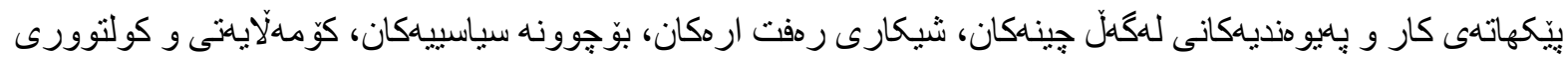

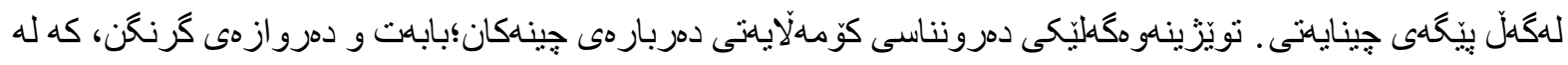

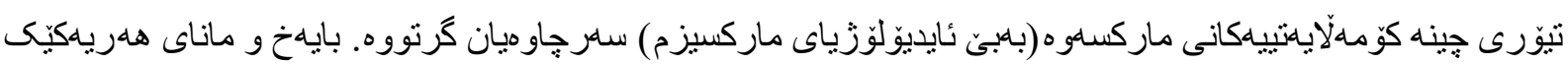

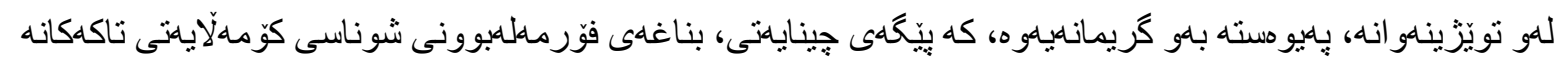

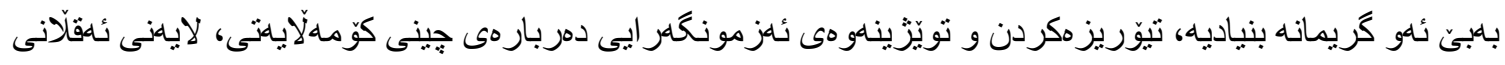

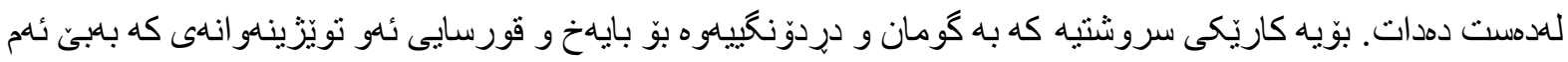

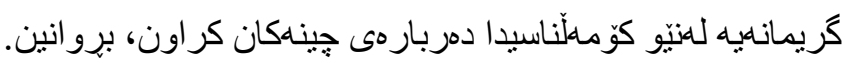

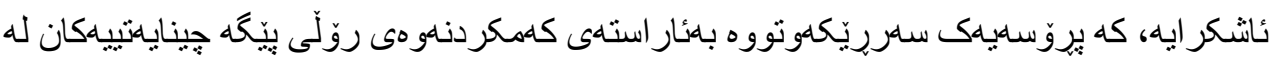

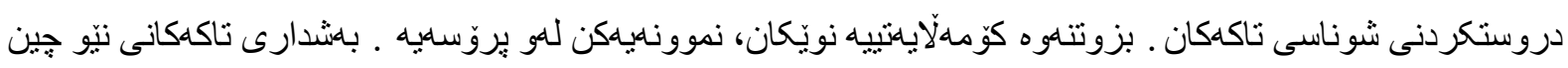

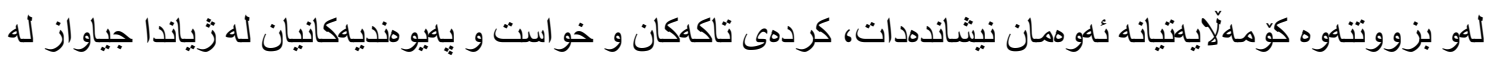

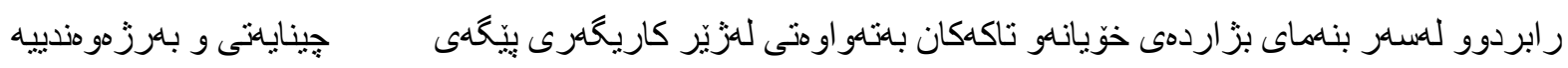

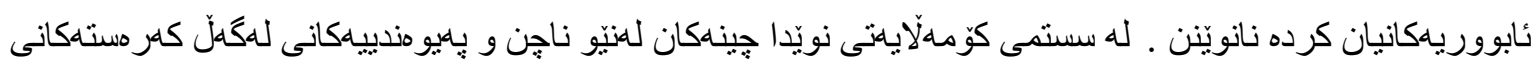

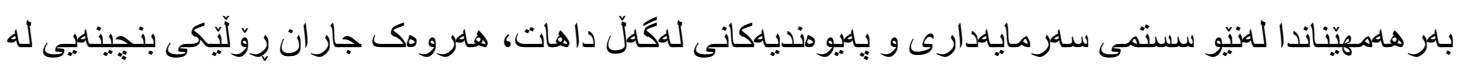

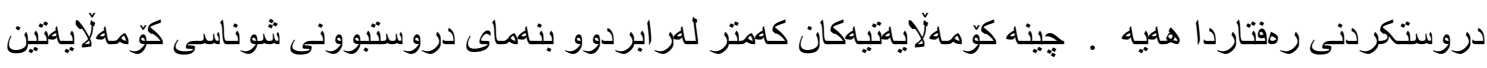

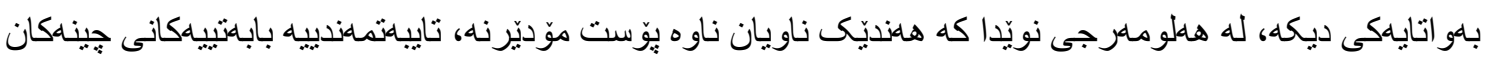

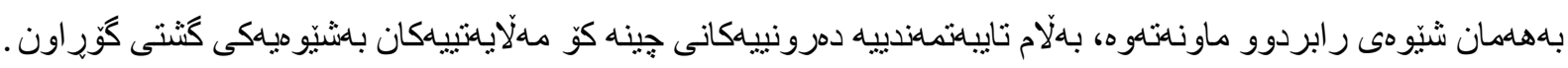

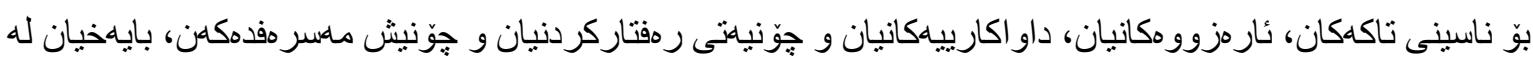

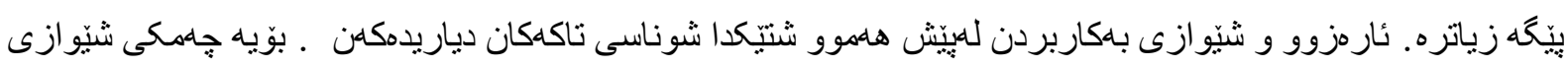

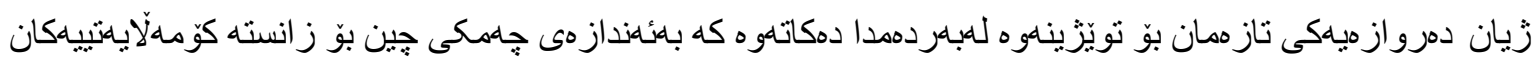

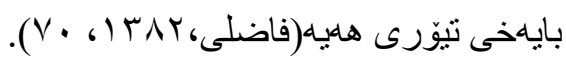




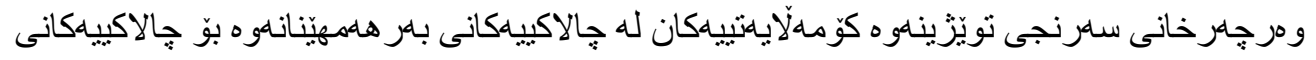

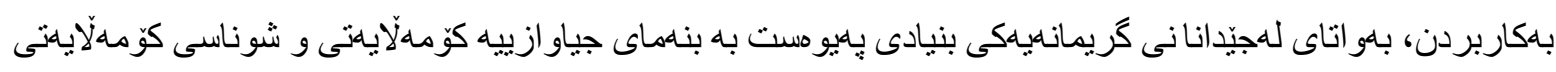
ديّت.

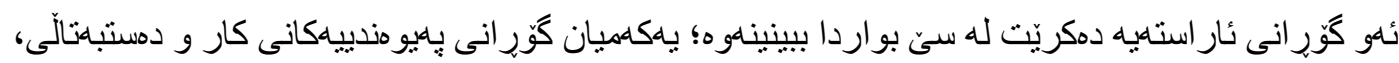

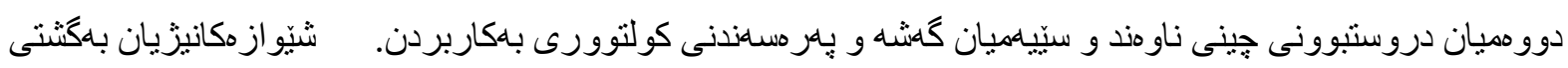

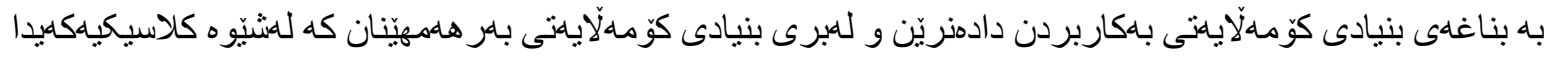

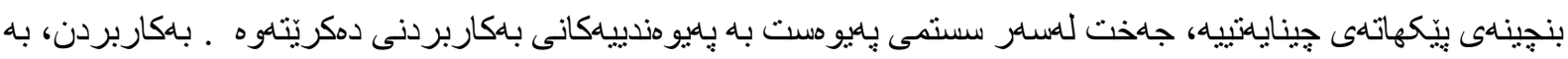

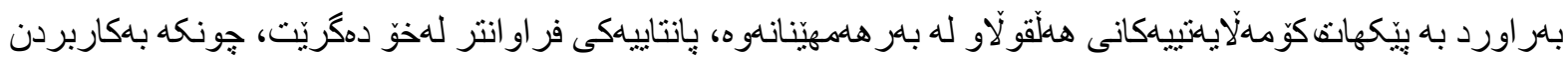

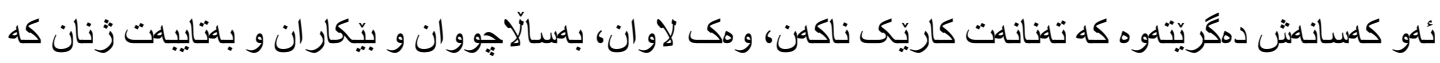

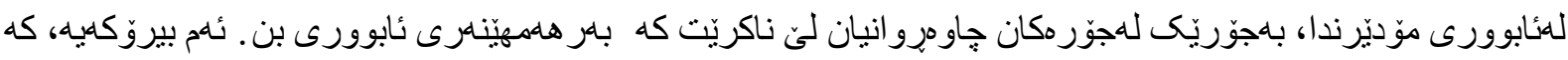

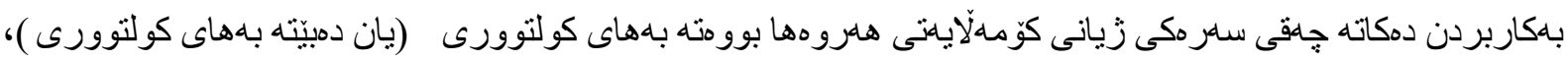

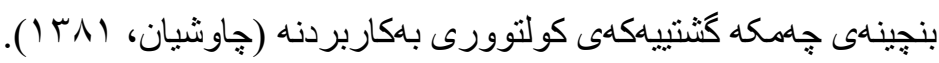

ئسنجام

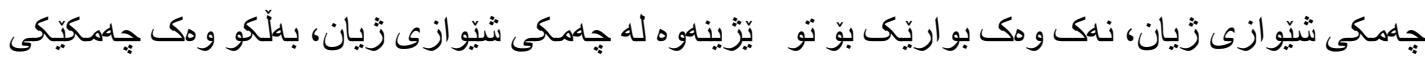

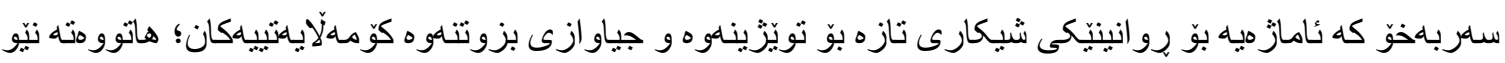

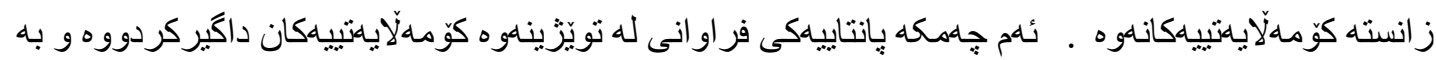

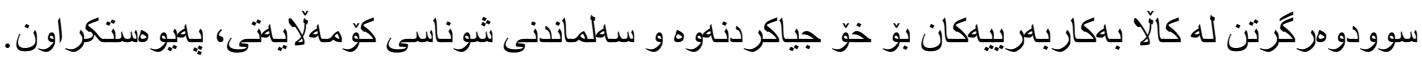

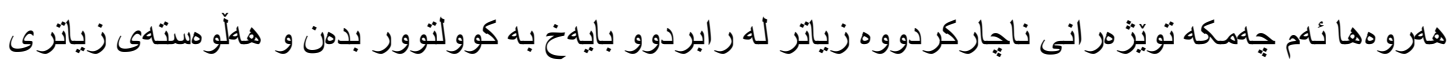

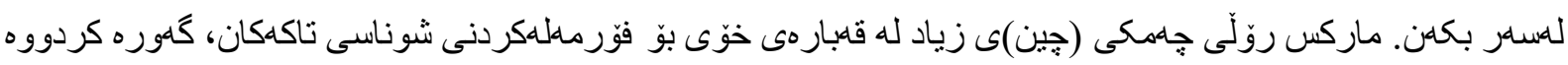

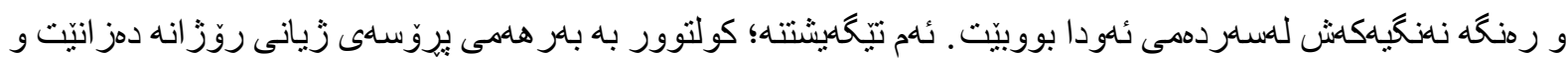

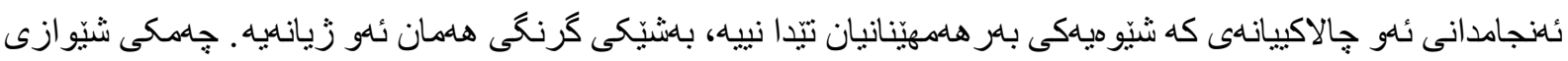

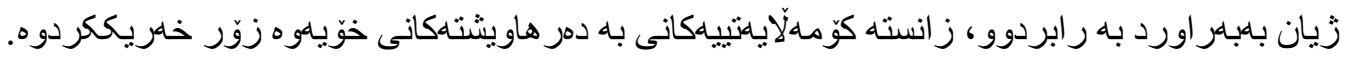

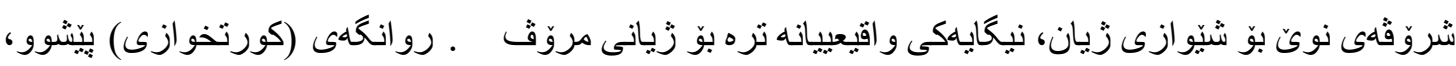

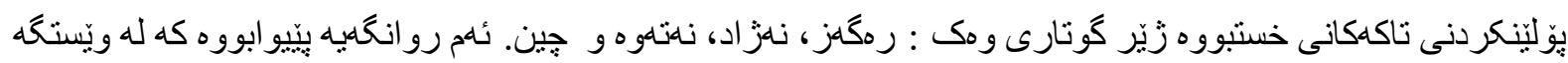

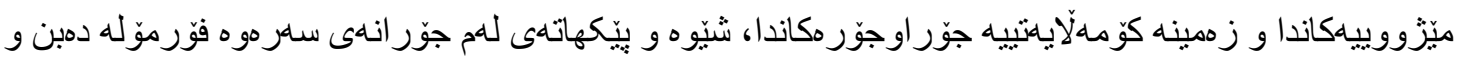

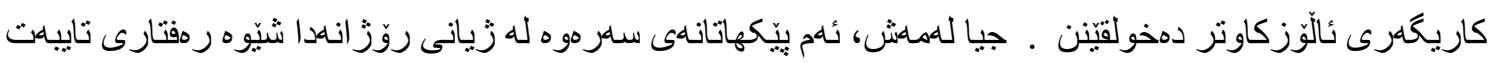

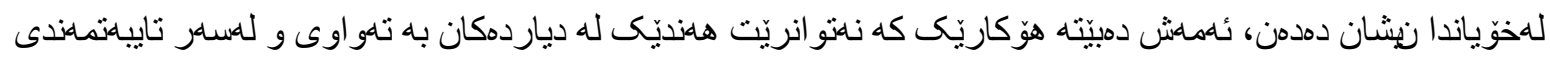

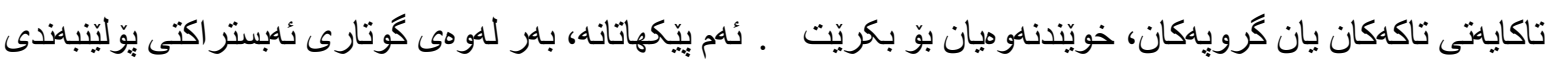

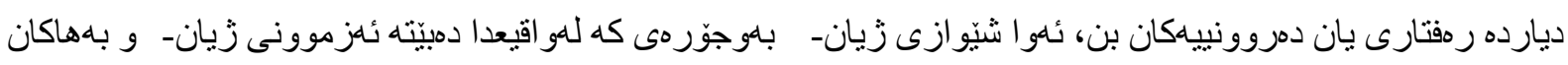

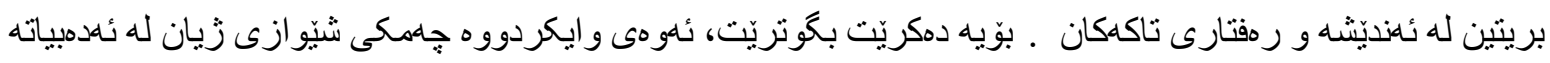

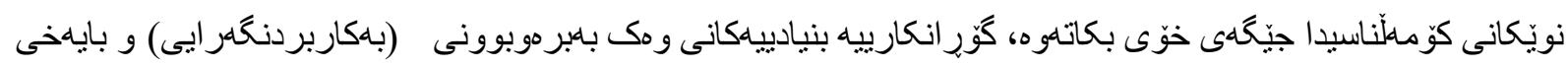

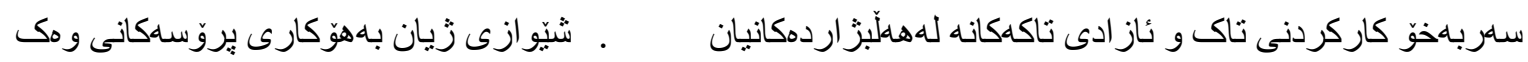

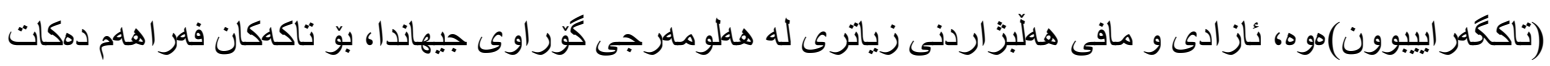




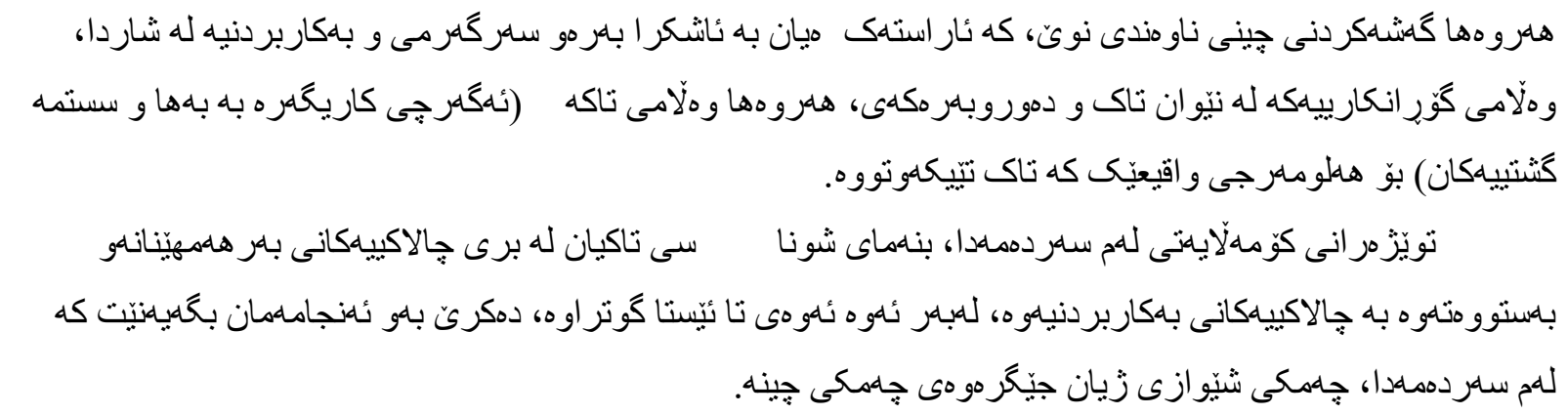

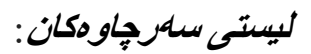

\section{REFERENCES}

Bourdieu, P. (1984). Distinction: A social critique of the judgement of taste. Harvard university press.

Bourdieu, P. (1998). Practical reason: On the theory of action. Stanford University Press.

Chawshyan, Hassan.(1996). Lifestyle and Social Identity.Tahran: Neshrny.

Fazly, Muhamad.(1997).Counsamption and Lifstyle.Tahran: qwm.

Gelaypur, Hamid Reza and Gemal mohammady.(2002). Past Theory of Sociology. Tahran: Ney.

Gibbins, J.R. and Reimer, B., (1999). The politics of postmodernity: An introduction to contemporary politics and culture. Sage.

Giddens, A. (1991). Modernity and self-identity: Self and society in the late modern age. Stanford university press.

Heijs, W., Carton, M., Smeets, J. and Van Gemert, A. (2009). The labyrinth of lifestyles. Journal of Housing and the Built Environment, 24(3), 347-356.

Mahdykny, Mohammad Said.(2001). Lifestyles Concept in Social Sicnce. No.1.

Mohammadpur, A. and Mahmoodi, K. (2016). Lifestyle and identity in contemporary Iranian Kurdistan (a grounded study of Marivan City). Quality \& Quantity, 50(5),1907-1928.

Nury, Bezhen, Ali Rohany and Sumaye Hashmy.(2005). Lifestyle and Managing. Journal of Fimels Research. No.4, 21-48.

Reimer, B. (1995). Youth and Modern Lifestyles, in Johan Fornas and Goran Bolin(Eds). Youth Culture in Late Modernity. Sage Publication.

Sobel, M. (1981).Lifestyle and Social Structure: Concepts, Definitions, and Analyses. Academic Press.

Veblen, T.(2007). Theory of the Leisure Class (Oxford world's classics).Transaction Publishers.

Zekay, Mohammad Said.(2005). Sub-Cultuer, Lifestyle and Identety. Rushd Group, 20-21. 
